OPEN ACCESS

Edited by:

Jan Fric,

International Clinical Research Center

(FNUSA-ICRC), Czechia

Reviewed by:

Stefania Gallucci,

Temple University, United States

Alexander Visekruna,

University of Marburg, Germany

*Correspondence: Santhakumar Manicassamy smanicassamy@augusta.edu

Specialty section: This article was submitted to

Molecular Innate Immunity,

a section of the journal

Frontiers in Immunology

Received: 06 April 2021

Accepted: 14 July 2021

Published: 29 July 2021

Citation:

Manoharan I, Prasad PD, Thangaraju M and Manicassamy S (2021) Lactate-Dependent Regulation of Immune Responses by Dendritic Cells and Macrophages.

Front. Immunol. 12:691134. doi: 10.3389/fimmu.2021.691134

\section{Lactate-Dependent Regulation of Immune Responses by Dendritic Cells and Macrophages}

\author{
Indumathi Manoharan ${ }^{1,2}$, Puttur D. Prasad ${ }^{2}$, Muthusamy Thangaraju ${ }^{2}$ \\ and Santhakumar Manicassamy 1,2,3* \\ 1 Georgia Cancer Center, Medical College of Georgia, Augusta University, Augusta, GA, United States, ${ }^{2}$ Department of \\ Biochemistry and Molecular Biology, Medical College of Georgia, Augusta University, Augusta, GA, United States, \\ ${ }^{3}$ Department of Medicine, Medical College of Georgia, Augusta University, Augusta, GA, United States
}

For decades, lactate has been considered an innocuous bystander metabolite of cellular metabolism. However, emerging studies show that lactate acts as a complex immunomodulatory molecule that controls innate and adaptive immune cells' effector functions. Thus, recent advances point to lactate as an essential and novel signaling molecule that shapes innate and adaptive immune responses in the intestine and systemic sites. Here, we review these recent advances in the context of the pleiotropic effects of lactate in regulating diverse functions of immune cells in the tissue microenvironment and under pathological conditions.

Keywords: dendritic cells, macrophages, lactate signaling, GPR81/GPR132, regulatory and inflammatory responses, antitumor immunity, immune response to infections, inflammatory diseases

\section{INTRODUCTION}

For decades, lactate has been considered a waste product of cellular metabolism. New lines of investigations now recognize this glycolytic metabolite as an active immune modulator that shapes the functions of immune cells in the tissue microenvironment and under pathological conditions (1-3). Accumulation of lactate in the tissue microenvironment is an essential feature of both inflammatory diseases and cancer (1-3). Much is known about the production of lactic acid under various disease conditions, while the mechanisms by which it shapes the effector functions of immune cells and restores tissue homeostasis remain obscure. Recent evidence suggests an emerging role for lactate in the field of inflammation, autoimmunity, and cancer (1-3). Here, we review our current knowledge of the role of lactate in regulating inflammatory and regulatory responses in various tissue environments, highlight some unanswered questions, and discuss how this new information can be exploited in the rational design of therapies against various autoimmune disorders, infections, and cancers.

\section{DENDRITIC CELLS AND MACROPHAGES IN REGULATING INFLAMMATORY AND REGULATORY RESPONSES}

The immune system launches robust immunity against foreign antigens while maintaining a state of tolerance to self-antigens, food antigens, and commensal flora (4-8). Loss of tolerance to self-antigens, 
food antigens, and commensal flora leads to immune cellmediated inflammatory diseases and autoimmunity (4-9). Dendritic cells (DCs) and macrophages are a specialized subset of antigen-presenting cells (APCs) that form a critical link between innate and adaptive immune cells. These APCs represent a complex immunological system composed of several functionally distinct subsets distributed in different organs and microenvironments (4-9). A detailed discussion of DC and macrophage subsets and their influence on adaptive immunity is outside the scope of the present review and was reviewed extensively recently (4-9). DCs and macrophages express a wide array of pathogen recognition receptors (PRRs) which enables them to sense different pathogen-associated molecular patterns (PAMPs) and damage-associated molecular pattern molecules (DAMPs) $(7,10)$. Signaling through PRRs activate and program APCs to induce distinct innate responses that shape the type of T-helper (Th) responses $(7,10)$. In addition to inducing robust immune responses against infections, DCs and macrophages also play a critical role in suppressing inflammatory responses and maintaining tissue immune homeostasis. Furthermore, DCs and macrophages induce immune tolerance and contribute to the resolution of inflammation through several regulatory mechanisms (11). However, the cellular and molecular mechanisms underlying this phenomenon remain poorly understood. Emerging studies suggest a fundamental role for lactate in the tissue microenvironment in regulating immunity and immune tolerance by shaping the functions of DCs and macrophages. Here, we will discuss how lactate shapes the functions of DCs and macrophages under steady-state and inflammatory conditions.

\section{LACTATE METABOLISM AND TRANSPORT IN DENDRITIC CELLS AND MACROPHAGES}

Upon activation, DCs and macrophages undergo profound metabolic changes critical for biosynthesis and energy production (12). Lactate could also serve as a fuel source to produce energy by various cell types, including immune, cancer, and stromal cells $(13,14)$. Like other cell types, APCs produce lactate under hypoxic conditions or by aerobic glycolysis. A phenomenon similar to the Warburg effect in tumors is also observed in DCs and macrophages following TLR activation which induces a major metabolic reprogramming characterized by a switch from oxidative phosphorylation (OXPHOS) to glycolysis. This metabolic shift reprograms APCs from a regulatory state to an inflammatory state and intracellular and extracellular lactate levels play an essential role in this process.

Under homeostatic conditions, intracellular and extracellular lactate levels are tightly regulated. Lactate production occurs in the cytoplasm within the cell due to hypoxic or aerobic glycolysis and accumulates in the extracellular space. Lactate dehydrogenases (LDHs) are critical enzymes in glycolysis that reversibly catalyze the conversion of pyruvate to lactate or lactate to pyruvate $(1,13)$. $\mathrm{LDH}$ is a tetrameric enzyme composed of two types of subunits namely LDH-A and LDH-B. LDH-A has a higher affinity for pyruvate and preferentially catalyzes pyruvate to L-lactate, while LDH-B has a higher affinity for lactate and converts L-lactate to pyruvate, fueling oxidative metabolism. Immune cells, including DCs and macrophages, express both LDH-A and LDH-B subunits (1). However, proinflammatory DCs and macrophages express higher levels of LDH-A and show increased production of lactate due to the sustained glycolytic reprogramming induced by TLR ligands. In DCs this metabolic shift depends on activating transcription factors such as sterol regulatory element-binding protein (SREBP) and hypoxia-inducible factor (HIF)-1 $\alpha$ (15). Furthermore, HIF- $1 \alpha$ plays a crucial role in regulating the expression of LDH-A and several other genes involved in glycolysis (15). Evidence suggests that HIF1 $\alpha$ deficiency in DCs and macrophages leads to loss of GLUT1 (a facilitative glucose transporter) and LDHA (16-18). Besides, HIF-1 $\alpha$ can be activated through a feedback mechanism by intracellular pyruvate or lactate $(19,20)$. However, whether this effect depends on SREBP or the direct control of inflammatory cytokine expression is unknown.

Lactate in the cell or extracellular space is transported across the plasma membrane by monocarboxylate transporters (MCTs) of the SLC16 solute carrier family, and they transport lactate by an $\mathrm{H}^{+}$coupled transport mechanism $(13,14,21,22)$. MCTs, prevent intracellular accumulation of lactate by removing excess lactate produced due to increased glycolytic activity $(23,24)$. Dendritic cells and macrophages express MCT1, MCT2 and MCT4 (13, 14, 22). MCT1 and MCT2 have a higher affinity for lactate and are primarily responsible for transporting lactate into the cells. MCT4 has a lower affinity for lactate and is primarily responsible for the export of lactate. Interestingly, lactate also regulates the expression of MCT1 and MCT4 (25). In addition to MCTs, two other solute carrier family 5 members (SLC5), namely SLC5A8 (SMCT1, sodiumcoupled monocarboxylate transporter 1) and SLC5A12 (SMCT2, sodium-coupled monocarboxylate transporter 2) can also mediate transmembrane transfer of lactate, and they transport lactate by a $\mathrm{Na}^{+}$-coupled transport mechanism. DCs, macrophages, and other immune cells express SLC5A8 and SLC5A12 (13, 14, 22). MCTs and SMCTs play a key role in lactate transport in APCs, yet their regulation and roles under steady-state and inflammatory conditions are incompletely understood.

\section{The Lactate-Mediated Signaling Pathway}

New lines of investigation now place lactate as an active signaling molecule that controls the differentiation and functions of immune cells under steady-state and inflammatory conditions. In addition, lactate exerts autocrine effects on the host cells and paracrine effects on other cell types in the tissue environment. Recent studies have revealed some of the signaling pathways by which lactate shapes the functions of DC and macrophage through receptor-dependent and receptor-independent mechanisms.

\section{LACTATE-GPR81 SIGNALING AXIS}

L-Lactate, a ubiquitous metabolite, functions as a natural ligand for GPR81 (HCAR1, hydroxy-carboxylic acid receptor) $(26,27)$. 
Lactate activates GPR81 in its physiological concentration range of 1-20 mM (17). GPR81 expression varies depending on the cell type and tissue microenvironment. For example, fat cells express high levels of GPR81 whereas secondary lymphoid tissues, gut, brain, kidney express low levels of GPR81 (26, 28, 29). Recently, several groups have reported that DCs and macrophages express GPR81, and its expression is regulated by the tissue microenvironment (29-32). Our recent work has shown that DCs and macrophages in the intestine and lung express higher levels of GPR81 compared with DCs and macrophages in the spleen (30). Likewise, DCs in the tumor microenvironment (TME) express high levels of GPR81 $(13,32)$. An important unresolved question is how the tissue microenvironment regulates GPR81 expression in these APCs. Adipocyte studies have shown that peroxisome proliferative-activated receptor $\gamma$ (PPAR $\gamma)$ transcriptionally regulates GPR81 expression $(27,33)$. Lipids and their metabolites are potent activators of the PPAR family transcription factors in APCs (34-36). These ligands are widely present in the intestine and TME suggesting that PPARmediated signaling might regulate GPR81 expression in APCs (34-36). Besides, recent studies have shown that lactate can regulate GPR81 expression in tumor cells via the snail3/STAT3 (signal transducer and activator of transcription 3) pathway (37). Further studies are warranted to see whether the PPAR $\gamma$ and snail3/STAT3 pathways regulate GPR81 expression in DCs and macrophages. Recent studies have highlighted a protective role for GPR81 in minimizing tissue injury by controlling pathological inflammatory responses (31). Lactate-GPR81 mediated signaling in non-immune cells regulates several key signaling pathways such as the cyclic adenosine monophosphate (cAMP), protein kinase A (PKA), and extracellular signalregulated kinase (ERK) pathways. However, the downstream signaling networks of GPR81 in DCs and macrophages are unknown. GPR81 suppresses inflammatory responses in monocytes and macrophages by limiting the activation of the $\beta$-arrestin/inflammasome pathway (31). In pDCs, GPR81 signaling regulates IFN $\alpha$ production by inducing intracellular $\mathrm{Ca}^{2+}$ mobilization and its downstream genes $\mathrm{Ca}^{2+} /$ calmodulin dependent protein kinase II (CaMKII), and calcineurin (CaN) phosphatase (38). In addition to modulating these pathways, other signaling pathways, such as inhibition of nuclear factorkappa $\mathrm{B}(\mathrm{NF}-\mathrm{KB})$, play a role in the anti-inflammatory function of lactate in macrophages. GPR81 signaling in macrophages exerts suppressive effects on NF- $\mathrm{KB}$ and yes-associated protein (YAP) activation via activation of AMP-activated protein kinase (AMPK) and large tumor suppressor kinases (LATS), resulting in reduced proinflammatory cytokine production after exposure to LPS (39) (Figure 1). In contrast to its anti-inflammatory role, an in vitro study has shown that lactate augmented LPS-induced expression of inflammatory genes by enhancing $\mathrm{NF}-\kappa \mathrm{B}$ activation in human monocyte-derived macrophages and U937 cells (40). In the TME, GPR81-signaling plays an essential role in immune suppression against tumors by inducing regulatory APCs (32) and upregulating the expression of programmed
A Receptor Independent Pathways

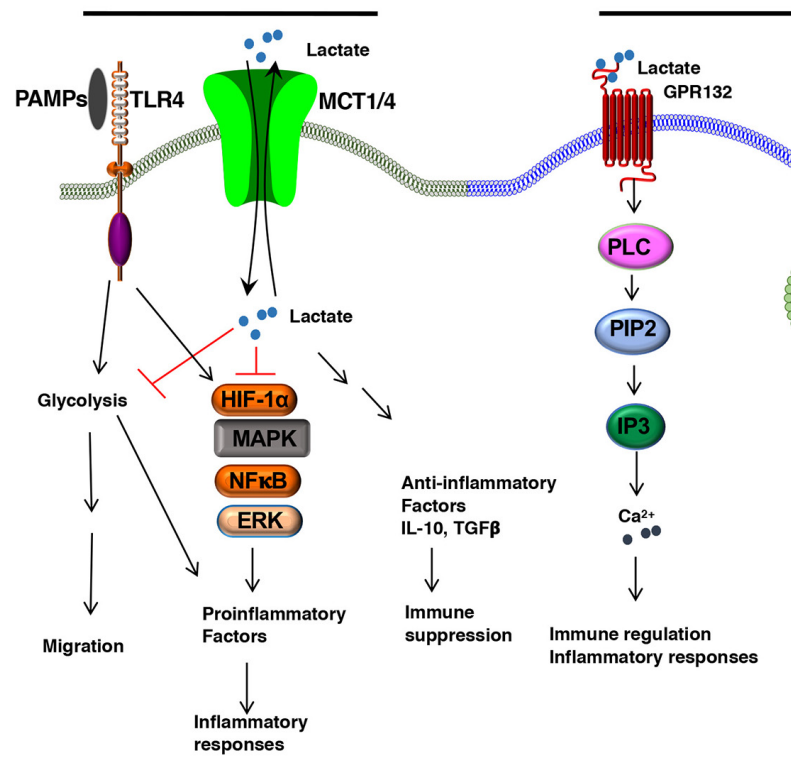

B Receptor Dependent Pathways

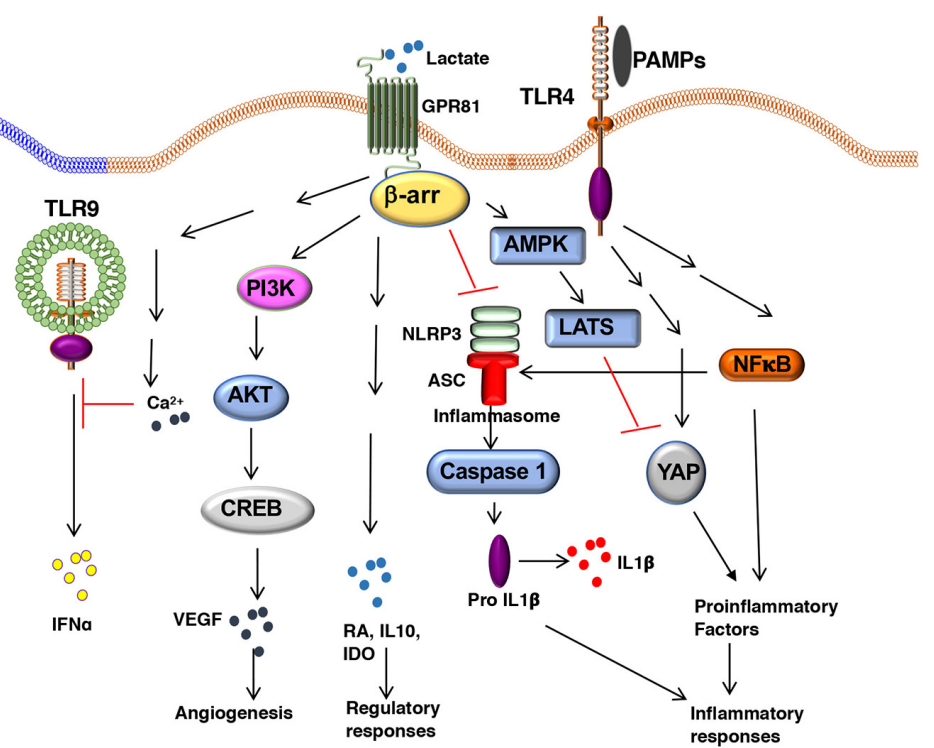

FIGURE 1 | The Lactate-mediated receptor-dependent and receptor-independent signaling pathways. Lactate binds to GPR81 and GPR132 receptors and activates several downstream signaling pathways and transcription factors in DCs and macrophages. (A) Lactate binding to GPR81 and GPR132 results in the activation or suppression of several downstream pathways such as PI3K/AKT/CREB, PLC/IP3/Ca ${ }^{2+}$, $\beta$-arrestin/inflammasome, AMPK/LATS/YAP/NF- $\kappa B$. This results in reduced expression of proinflammatory cytokine production and increased expression of immune regulatory factors (IL-10, IDO, RA, TGF $\beta$ ) in response to TLR ligands. (B) Lactate can shape APC functions independent of surface receptors. MCTs transport extracellular lactate into the cells, and intracellular lactate can modulate APC functions by directly regulating the activation of multiple signaling pathways and transcription factors such as HIF-1 $\alpha$, MAPK, ERK, and NF- $\mathrm{KB}$. 
death-ligand 1 (PD-L1) in tumor cells (25). Collectively, these studies show a regulatory role for the lactate-GPR81 signaling axis in DCs and macrophages. GPR81 signaling in tumor cells regulates MCT1 and MCT4 (25), but underlying molecular mechanisms remain largely unknown. The extent to which GPR81 signaling regulates the expression of MCT1 and MCT4 in DCs and macrophages remains to be determined.

\section{LACTATE-GPR132 SIGNALING AXIS}

A second functional receptor for lactate in macrophages is the $G$ protein-coupled receptor 132 (Gpr132, also known as G2A) (41, 42). Besides lactate, lysophosphatidylcholine (lysoPC) is also a ligand for GPR132 (43). GPR132 is a stress-inducible, seven-pass transmembrane receptor that actively modulates several cellular and biological activities, such as cell cycle, proliferation, and immunity $(44,45)$. Tumor-associated macrophages (TAMs) promote metastasis $(46,47)$, and GPR132 signaling plays a crucial role in promoting breast cancer metastasis (41). Mechanistically, the lactate-GPR132 axis promotes the alternatively activated macrophage (M2)-like phenotype, which, in turn, facilitates cancer cell adhesion, migration, and invasion (41). Consequently, GPR132 deletion reduces M2 macrophages and impedes breast cancer lung metastasis in mice. Interestingly, GPR132 regulating macrophage function may vary depending on the tissue microenvironment $(41,42)$. Like GPR81, GPR132 plays a crucial role in regulating inflammation in the intestine (48). GPR132mediated signaling activates several downstream signaling pathways associated with immune regulation and inflammatory responses such as cAMP, protein kinase A (PKA), and ERK (48) (Figure 1). However, the role of GPR132 in intestinal macrophages and DCs remain largely unknown.

\section{RECEPTOR-INDEPENDENT LACTATE SIGNALING}

In addition to signaling via cell surface receptors, extracellular lactate can also modulate the APC's functions by directly regulating the activation of multiple signaling pathways and transcription factors after getting transported into the cells through MCTs and SMCTs (14). In this context, ex vivo studies have shown that lactate metabolically reprograms macrophages to inhibit the expression of proinflammatory factors in response to LPS in a GPR81-independent manner (29). Under hypoxic conditions, lactate can modulate DC and macrophage functions by regulating other signaling pathways such as the HIF- $1 \alpha$, Hedgehog, MAPK, and mTOR pathways (49) (Figure 1). Histone deacetylases (HDACs) regulate gene transcription and chromatin assembly at the posttranscriptional levels by modifying histones (50). HDAC inhibitors exhibited anti-inflammatory effects and were shown to ameliorate immune cell-mediated inflammatory diseases (50). For instance, strong evidence shows that intracellular lactate acts as an endogenous inhibitor of HDACs and regulates gene transcription in an HDAC-dependent manner $(51,52)$. Further, studies are warranted to see whether lactate regulates gene transcription in DCs and macrophages via the inhibition of HDACs.

\section{MODULATION OF DC AND MACROPHAGE FUNCTIONS BY LACTATE}

Robust immune responses against pathogens and tumors depend on several factors, such as the degree of maturation and activation of DCs, their ability to capture, process, and present exogenous antigens, them trafficking to secondary lymphoid organs and tissues type of factors they produce. Emerging studies have shown that lactate-mediated signaling is crucial in shaping immune responses by modulating DC and macrophage functions (Figure 2 and Table 1). Here, we will discuss how lactate shapes essential functions of DCs and macrophages that influence adaptive immune responses.

\section{REGULATION OF DC MATURATION AND ACTIVATION BY LACTATE}

DC maturation and activation are important in inducing a robust immune response against tumors and pathogens (11). Immature or tolerogenic DCs facilitate tolerance or immune regulatory responses, whereas immunogenic/inflammatory DCs facilitate robust inflammatory responses (7). Under homeostatic conditions, peripheral DCs typically display an immature phenotype characterized by low surface levels of MHC II and costimulatory molecules and induce suboptimal T-cell priming, often leading to Tcell anergy or tolerance. Upon stimulation, DCs undergo maturation characterized by the expression of high levels of MHC II and costimulatory molecules (CD80, CD86, and CD40) and induce robust $\mathrm{T}$-cell activation and effector differentiation (7). However, certain stimuli induce the tolerogenic/regulatory DCs that express markedly lower costimulatory molecules and induce regulatory $\mathrm{T}$ cells and immune suppression. Several reports have shown that lactate-mediated signaling blocks DC differentiation, activation and antigen presentation $(53,60)$. Exposure to lactate conditions DCs to a regulatory or anti-inflammatory state. Earlier ex vivo studies have shown that DCs cultured in the presence of lactate exhibit regulatory functions (53-59). These regulatory DCs expressed low surface levels of MHC II and costimulatory molecules and produced markedly lower levels of IL-12 and higher levels of IL-10. Besides, a recent study has shown that human tolerogenic DCs produce high levels of lactate that shape $\mathrm{T}$ cell responses toward tolerance and delayed graftversus-host disease (91). Like DCs, lactate exposure polarizes macrophages to M2 phenotype with increased expression of CD163 and Arg1 and decreased expression of M1 markers such as CD38, iNOS, IL-1 $\beta$, and IL-6 (41). This lactate effect on TAMs depends on NRF2 (nuclear factor erythroid 2-related factor 2), HIF$1 \alpha$, and $\operatorname{MCT} 1(20,78,79)$.

DCs and macrophages recognize diverse microbial structures through multiple receptors collectively known as PRRs (10). DCs and macrophages can also recognize damage-associated molecular patterns (DAMPs) and other endogenous ligands released from dying tumor cells through PPRs (92-94). 


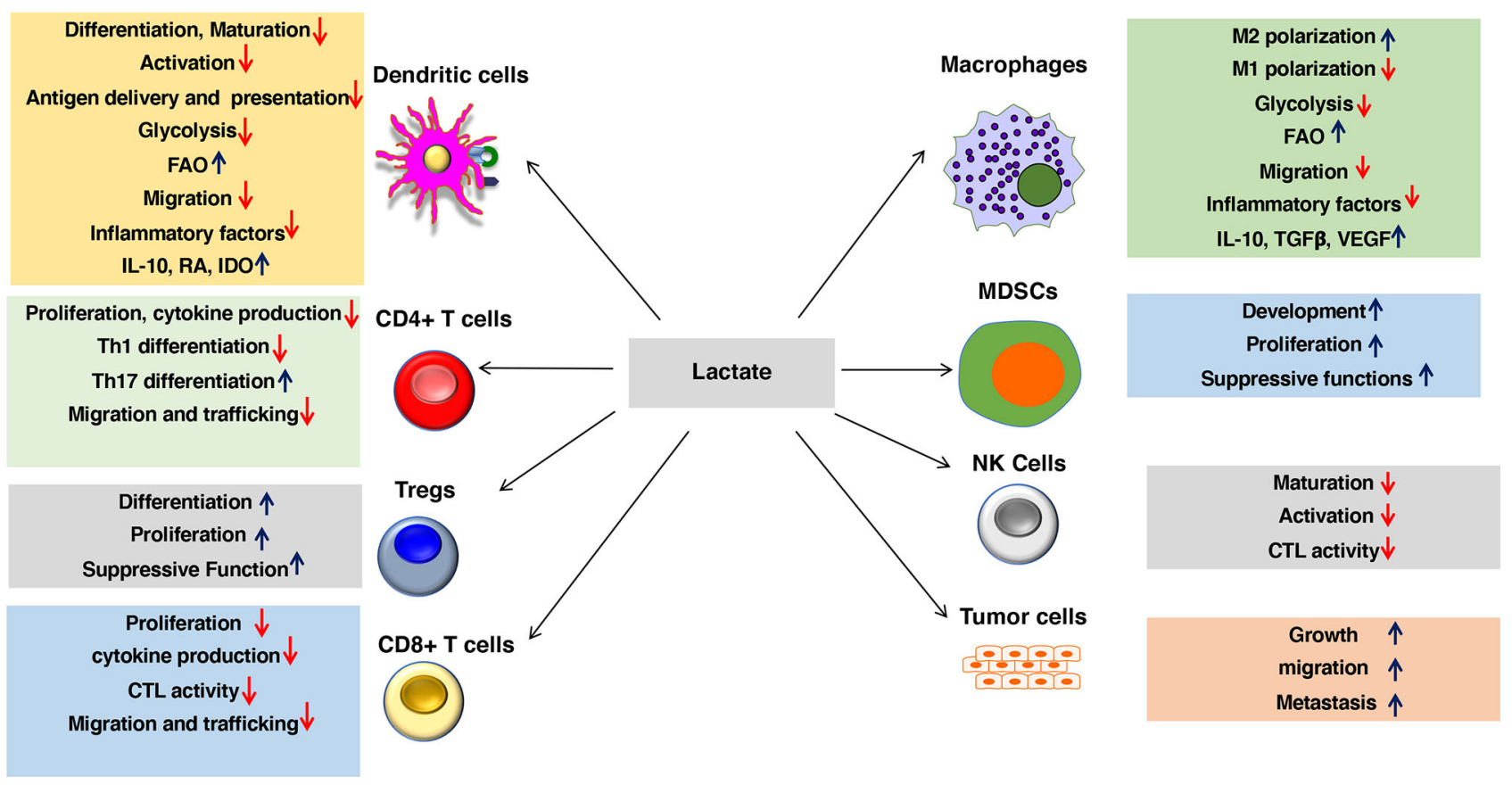

FIGURE 2 | Lactate in the environment shapes the functions of both innate and adaptive immune cells. Lactate promotes anti-inflammatory and antitumor immune responses by modulating DC and macrophage functions such as activation, trafficking, capturing, and cross-presenting antigens and expression of immune regulatory and inflammatory factors. Besides, lactate signaling cascade directly shapes the activation, proliferation, and effector phenotypes of myeloid-derived suppressor cells (MDSCs), Tregs, CD4 ${ }^{+} \mathrm{T}$ cells, $\mathrm{CD}^{+} \mathrm{T}$ cells, NK cells, and other immune cells. Lactate also regulates trafficking and migration of immune cells to tissues and draining lymph nodes (DLNs) by regulating chemokine receptors as well as synthesis and secretion of chemokines. Lactate signaling in the immune cell leads to metabolic alterations in DCs and macrophages that programs them to a regulatory state. Lactate-mediated signaling shifts metabolism of DCs and macrophages from glycolysis to fatty acid oxidation (FAO). Besides, lactate signaling in tumors and macrophages promotes tumor growth, migration, and metastasis.

PRRs include Toll-like receptors (TLRs), C-type lectin-like receptors (CLRs), RIG-I-like receptors (RLRs), and Nod-like receptors (NLRs) (10). TLR ligands have gained significant interest in immunotherapy in recent years for their potential use as vaccine adjuvants $(95,96)$. In general, PRR engagement potently activates DCs by upregulating the surface expression of maturation markers such as MHCII, CD80, CD83, and CD86 (10). Even though PRR ligands are there in the TME and mucosal organs (92-94), DCs and macrophages present in these environments display markedly decreased expression of costimulatory molecules (97). Earlier ex vivo studies on human and murine DCs have shown that exposure to lactate markedly affected the maturation and activation in response to LPS $(31,53)$. Lactate also inhibited the LPS-mediated activation of bone marrow-derived macrophages and peritoneal macrophages. Lactate-conditioned macrophages failed to upregulate costimulatory molecules while expressing lower levels of proinflammatory cytokines and higher levels of IL-10 even in response to TLR ligands $(29,31,39,98)$. Further, mechanistic studies have shown that lactate signaling can negatively regulate the inflammatory pathways such as the NF-kB, NFAT (nuclear factor of activated T-cells), YAP, inflammasome, and MAPK (mitogen-activated protein kinases) pathways, critical for DC activation and expression of inflammatory factors $(31,59)$. Accordingly, DCs and macrophages that are deficient in GPR81 are hyper-responsive to TLR ligands (30). Also, other studies revealed the role of monocarboxylate transporters (MCTs) in mediating the lactate effect in macrophages (77). MCT4 inhibition significantly boosted lactate-induced M2 polarization, while blocking of MCT1/2 failed to reverse the immunosuppressive effect of lactate, correlating with the results from gene expression studies that showed lactate increasing MCT4 expression but downregulating the expression of MCT1/2 (59). Thus, the effects of lactate on the maturation and activation of DCs and macrophages involve GPR81 dependent and independent mechanisms via MCTs.

\section{REGULATION OF DENDRITIC CELL MIGRATION BY LACTATE}

The migration of DCs to secondary lymphoid organs and tissues is essential for initiating adaptive immune responses, tumor immune surveillance, regulation of inflammation in the tissues, and selective elimination of infected cells $(99,100)$. DC migration involves its trafficking to tissues, capturing and endocytosing dead or infected cells, and transporting associated antigens to the draining lymph nodes (TDLNs) where they prime and activate $\mathrm{T}$ cells to initiate adaptive immune responses (101-104). DC migration depends on the expression of specific chemokine receptors on DCs and its 
TABLE 1 | Evidence for involvement of the lactate in the microenvironment in shaping the functions of innate and adaptive immune cells.

\section{Lactate effects on DC function}

Lactate suppresses DC differentiation and maturation.

Lactate suppresses the activation of DCs and the expression of proinflammatory factors in response to TLR ligands.

Lactate inhibits antigen delivery and presentation by DCs.

Lactate accelerates antigen degradation in DCs by downregulating membrane trafficking proteins.

Lactate-GPR81 signaling in intestinal DCs induces the expression of immune regulatory factors to induce Tregs and suppresses the differentiation of

Th1/Th17 cells.

Lactate in the TME conditions DCs to a regulatory state to suppress antitumor immune responses.

Tumor DCs-deficient in GPR81 are more potent in inducing antitumor immunity.

Lactate signaling regulates the expression of chemokine receptors and chemokines that are critical for DC migration.

Lactate signaling in DCs regulates metabolic pathways involving glycolysis and fatty acid oxidation (FAO)

Lactate effects on $\mathrm{T}$ cells

Lactate suppresses T cell proliferation, cytokine production and Th1 differentiation.

Lactate promotes Treg proliferation and functions.

Under inflammatory conditions, lactate signaling in $\mathrm{CD}^{+}{ }^{+} \mathrm{T}$ cells favors Th17 cell differentiation.

Lactate suppresses the $T$ cell migration and trafficking.

Tumor-derived lactate limits the expansion of tumor-antigen specific $\mathrm{CD}^{+} \mathrm{T}$ cells, cytokine production, CTL activity.

Lactate synergizes with IL-21 to promote stemness of $C D 8^{+} \mathrm{T}$ cells and antitumor immunity.

Lactate effects on macrophage

Lactate induces alternative polarization (M2) of macrophages.

Lactate signaling in macrophages attenuates TLR-induced proinflammatory cytokine production.

Lactate signaling in TAMs promotes tumor growth, migration, metastasis, and immunosuppression.

(53-59)

$(31,53)$

$(53,60-62)$

(57)

(30)

(53, 60-62)

(32)

(53, 63-65)

$(60,66)$

(67-69)

$(67,70-72)$

$(73,74)$

$(73,74)$

$(75,76)$

(70)

Lactate-GPR132 signaling in macrophages contributes to tumor cell invasiveness and tumor growth.

Lactate-GPR81 signaling imparts regulatory phenotype on intestinal macrophages and induces the expression of immune regulatory factors to induce

Tregs.

Lactate-GPR81 signaling in macrophages suppresses expression of inflammatory factors in response to LPS.

Lactate effects on MDSCs

Lactate promotes the development and accumulation of MDSCs in tumors.

Lactate-conditioned MDSCs inhibit the function of natural killer (NK) cells and T lymphocytes

Lactate effects on NK cells

Tumor-derived lactic acid inhibits natural killer (NK) cell maturation and function.

$(29,41,77)$

$(31,39,59)$

$(20,41,78-80)$

$(41,80,81)$

(65)

(30)

$(31,39)$

$(83,84)$

Lactate effects on other immune cells

Lactate regulates the functions of basophils, neutrophils, mast cells

$(75)$

$(85-88)$

Lactate effects on Tumor cells

Lactate promotes tumor growth, migration, and metastasis,

$(13,89,90)$

cognate chemokine ligand within the tissues and DLNs. DC migration to DLNs requires chemokine receptor CCR7, whereas its recruitment to the tissues depends on chemokines such as CCL4, CCL5, and XCL1 (99). However, only a tiny fraction of DCs migrate to tumor tissue and subsequently to the draining lymph nodes. Glycolytic metabolism is essential for CCR7 oligomerization and DC migration (94). Blocking glycolysis impairs CCR7 oligomerization and impairs migration (63). Ex vivo studies have shown that high lactate levels $(20 \mathrm{mM})$ inhibited the migration of monocytes and DCs $(53,64)$. Similarly, lactate regulates macrophage functions such as adhesion, migration, and tissue recruitment (41, 80, 81). Furthermore, lactate in the TME and inflamed tissues can regulate the migration of immune cells by regulating the expression of several key enzymes involved in glycolysis (105).

\section{REGULATION OF ANTIGEN DELIVERY AND PRESENTATION BY LACTATE}

Cross-presentation is critical for initiating immune responses against tumors and viral infections, where DCs present extracellular antigens on MHC I to activate $\mathrm{CD}^{+} \mathrm{T}$ cellmediated cytotoxicity (10). Effective cross-presenting involves uptake of extracellular antigens, processing antigens into peptides, loading peptides onto MHC I, and trafficking of MHC I: peptide complex to the cell's surface (106). Membrane trafficking proteins such as SNARE (soluble n-ethylmaleimidesensitive factor attachment protein receptor) and VAMP3 (vesicle-associated membrane protein 3) play a critical role in cross-presentation. Loss of these membrane trafficking proteins in DCs leads to defective cross-presentation of tumor-associated antigens (57). DCs within the TME are less efficient in crosspriming $\mathrm{CD}^{+} \mathrm{T}$ cells $(61,62)$, and the TME contains high lactate levels. Emerging evidence has shown that lactate affects DCs' function by regulating antigen presentation and cross-priming $\mathrm{CD}^{+} \mathrm{T}$ cells $(53,60)$. However, the underlying molecular mechanisms by which lactate affects cross-presentation are not known. In this context, a recent study has shown that lactate can affect cross-presentation by downregulating membrane trafficking proteins such as SNAREs and VAMP3 while accelerating antigen degradation in DCs (57). Furthermore, these proteins facilitate the secretion of cytokines from DCs upon activation. Further studies are warranted to see whether the 
regulation of membrane trafficking proteins by lactate is dependent on GPR81 and MCTs. These studies collectively suggest that the lactate-mediated signaling suppresses efficient capture of tumor-associated antigens by tumor DCs and crosspriming of $\mathrm{CD}^{+} \mathrm{T}$ cells.

\section{REGULATION OF IMMUNE REGULATORY AND INFLAMMATORY FACTORS BY LACTATE}

DCs dictate the fate of naïve $\mathrm{CD} 4^{+}$and $\mathrm{CD} 8^{+} \mathrm{T}$ cells through differential production of pro- and anti-inflammatory cytokines $(11,107)$. Recent studies have shown that lactate can shape the adaptive immune responses by regulating the expression of immune regulatory factors and inflammatory factors in DCs and macrophages (108-113). DCs and macrophages exposed to TLR-ligands produce markedly higher levels of proinflammatory cytokines and type-I interferons (IFN). In contrast, lactateconditioned DCs and macrophages do not release immunostimulatory cytokines; instead, they express higher levels of IL-10 in response to TLR ligands $(53-55,57,58)$. The TME contains higher levels of immune regulatory factors such as IL-10, retinoic acid (RA), and TGF- $\beta$ that actively suppress differentiation and expansion of tumor-specific effector T cells $(114,115)$. Lactate in the TME condition DCs and macrophages to a regulatory or anti-inflammatory state $(1,2)$. Accordingly, tumor DCs deficient in the lactate receptor GPR81 expressed markedly higher levels of IL-12 and IL-6 (32). Similarly, lactateGPR81 signaling influences the pDC functions in tumors by attenuating IFN $\alpha$ production (38). Furthermore, blocking GPR81 signaling can restore the IFN $\alpha$ production by pDCs. Lactate in the TME conditions DCs and macrophages to express higher levels of IL-10 $(1,2)$. The effects of lactate on the expression of the regulatory and inflammatory cytokines in APCs also depend on MCTs. Furthermore, blocking the MCT in DCs or macrophages can reprogram them to an inflammatory state (59). These APCs produce high levels of inflammatory factors in response to TLR ligands (38). In the intestine, antiinflammatory factors such as IL-10, TGF- $\beta$, IDO, and RA produced by DCs and macrophages are critical for maintaining immune tolerance to commensal flora $(116,117)$. These immune regulatory factors are also necessary to suppress inflammation and restore immune homeostasis in the intestine. A recent study has highlighted an essential role for the lactate-GPR81 signaling in intestinal DCs and macrophages in regulating the expression of immune regulatory factors such as IL-10, retinoic acid (RA), and IDO (30). Intestinal DCs and macrophages isolated from GPR81 deficient mice produced markedly higher levels of inflammatory cytokines and lower levels of anti-inflammatory factors under homeostatic and inflammatory conditions (30). Furthermore, GPR81-deficient intestinal APCs are hyperresponsive to microbial ligands and express higher levels of proinflammatory cytokines (30). Collectively, these studies demonstrate that lactate-mediated signaling imparts an antiinflammatory phenotype to DCs and macrophages.

\section{REGULATION OF IMMUNE CELL METABOLISM BY LACTATE}

Cellular metabolic pathways play a critical role in modulating the functions of DCs and macrophages $(12,56)$, and emerging evidence support lactate as one of the essential molecules that links metabolism and immunity. DC and macrophage subsets have potential metabolic differences under homeostatic and inflammatory conditions $(12,56)$. Tolerogenic or regulatory DCs and macrophages show a catabolic metabolism marked by increased oxidative phosphorylation, fatty acid oxidation (FAO), and glutaminolysis $(12,56)$. In contrast, immunogenic or inflammatory DCs display an anabolic metabolism marked by increased glycolysis and lactate production $(12,56)$. Preliminary evidence suggests that lactate mediates immune cell-intrinsic effects on metabolism (73). Besides, extracellular lactate induces metabolic reprogramming of DCs and macrophages, resulting in reduced glycolysis and increased FAO $(29,60,66)$. This metabolic reprogramming of APCs significantly changes cytokine production with predominantly anti-inflammatory effects, emphasizing the complex interplay between metabolism and APC functions $(29,60,66)$. The effects of lactate on immune cell metabolism may serve as a negative feedback signal limiting inflammation (3). For example, lactate can modulate APC functions by regulating the expression of critical enzymes involved in glycolysis (3). These studies show that lactate imparts regulatory phenotype on APCs by metabolic reprogramming.

\section{EFFECTS OF LACTATE IN MODULATING THE FUNCTIONS OF OTHER IMMUNE CELLS}

Emerging studies are beginning to provide insights into the mechanisms by which lactate signaling cascade directly shapes the effector phenotypes of myeloid-derived suppressor cells (MDSCs), Tregs, $\mathrm{CD}^{+} \mathrm{T}$ cells, $\mathrm{CD}^{+} \mathrm{T}$ cells, and natural killer (NK) cells. Several excellent studies and reviews discuss extensively how extracellular lactate shapes the functions of other immune cells $(12,56)$ and will thus be discussed only briefly (Table 1). Lactate can exhibit a proinflammatory or antiinflammatory effect depending on the microenvironment and immune cell type conditions and factors. For example, lactate exerts an immune-suppressive role in the TME, whereas lactate exerts an inflammatory role in chronic conditions like arthritis. Lactate in the TME promotes expansion and accumulation of MDSCs while suppressing the effector functions of NK cells, $\mathrm{CD}^{+} \mathrm{T}$ lymphocytes, CTLs and mast cells (83-85). On the other hand, under chronic inflammatory conditions, lactate manifests an inflammatory role on $\mathrm{CD} 4^{+} \mathrm{T}$ cells by promoting the differentiation of Th17 cells (73). Effect of lactate on Th17 cell differentiation is $\mathrm{T}$ cell-intrinsic, but the underlying molecular mechanism is unknown and requires further investigation. These studies collectively show that the multi-faceted effect of lactate on the immune response is dependent on cellular and environmental contexts. 


\section{REGULATION OF AUTOIMMUNITY AND ANTITUMOR IMMUNITY BY LACTATE}

Accumulation of lactate in the tissue microenvironment is a feature of both inflammatory disease and cancer. Emerging evidence suggests that this is due to metabolic disturbances in immune cells. Lactate exhibits an inflammatory or anti-inflammatory role depending on its effects on immune cell type, disease type, and tissue environment $(12,56)$. This section will review recent developments in our understanding of the role of lactate-mediated signaling in regulating immune responses in pathological conditions.

\section{INFLAMMATORY BOWEL DISEASE (IBD)}

Loss of immune tolerance to intestinal commensal flora and oral antigens leads to chronic intestinal inflammation and inflammatory bowel disease (IBD). In the colon, lactate is one of the primary metabolites produced by bacterial fermentation of dietary products and gastrointestinal mucosa is exposed to high concentrations of lactate $(66,73,117)$. Besides, intestinal epithelial cells and immune cells can produce lactate (118-120). Initial study on murine models of IBD showed that the intrarectal treatment with lactate prevents intestinal inflammation by downregulating proinflammatory response in epithelial cells (121). However, whether lactate regulates immune responses to gut commensal flora remains largely unknown. Our recent work has revealed an essential role for GPR81 in programming tolerogenic DCs and macrophages in the intestine (30). Mice deficient in GPR81 are highly susceptible to chemically-induced colitis and $\mathrm{T}$ cell-mediated colitis. Besides, genetic deletion of GPR81 in mice led to loss of immune homeostasis in the intestine, which enhanced susceptibility to colonic inflammation (30). Besides intestinal APCs, lactate plays a crucial role in intestinal stem-cell-mediated regeneration of the epithelial layer through the GPR81-Wnt signaling pathway (122). This observation is particularly relevant in the intestine, given the importance of Wnt signaling in intestinal DCs and macrophages in regulating immune tolerance and commensal homeostasis in the intestine $(123,124)$. It would be interesting to see how lactate and Wnt signaling pathways cross-regulate each other in establishing immune tolerance and commensal homeostasis in the gut. In a striking functional similarity with GPR81 knockout mice, genetic deficiency of GPR132 also resulted in significantly worsened chemically-induced colitis in mice $(48,125)$. However, GPR132 deficiency does not alter intestinal immune homeostasis under homeostatic conditions. GPR132-mediated signaling in myeloid and lymphoid cells limits intestinal inflammation in a mouse model of colitis induced by dextran sodium sulfate (125). Collectively, these studies have identified a new and essential role for lactate, GPR81, and GPR132 signaling pathways in regulating immune tolerance and colonic inflammation.

\section{OTHER IMMUNE-MEDIATED INFLAMMATORY DISEASES}

Lactate plays a protective role in murine models of immune hepatitis and pancreatitis (31). In this model, the lactate- mediated protective effect is dependent on GPR81 signaling that limits the expression of proinflammatory factors by macrophages. Mice deficient in GPR81 are highly susceptible to LPS-induced hepatitis and pancreatitis. Confirming this finding, pharmacological activation of GPR81 decreased LPSinduced activation of the caspase- 1 and NF- $\mathrm{KB}$ pathways and production of proinflammatory factors by macrophages and reduced disease severity in mice (31). Lactate plays a similar anti-inflammatory role in Multiple sclerosis (MS). MS is a chronic inflammatory demyelinating neurological disease of the central nervous system (CNS). In the experimental autoimmune encephalomyelitis (EAE) model of MS, macrophages in the CNS display higher expression of LDHA and increased glycolysis (126). CNS macrophages also expressed higher levels of MCT4. siRNA-mediated knockdown of LDHA and MCT4 or blocking MCT4 reduced leukocyte infiltration and the clinical severity of EAE (126). However, the effects of lactate on the functions of DCs and other immune cells in this chronic inflammatory disease are not known.

In contrast to its regulatory and protective role, lactate significantly induces and promotes inflammation in rheumatoid arthritis (RA) (1). RA is a chronic inflammatory disease that affects joint linings causing pain, swelling, and deformity (127). The inflamed synovial tissue microenvironment includes an increased number of inflammatory DCs, macrophages and pathological effector $\mathrm{T}$ cells. Recent studies have revealed that lactate exacerbates disease severity by regulating migration of immune cells in the arthritic synovium $(73,74)$. Mainly, lactate inhibits T cell motility, which contributes to their entrapment in the inflammatory site. This depends on the lactate transporters SLC5A12 and SLC16A1 (MCT1) $(73,74)$. In addition, lactate also drives the differentiation of $\mathrm{T}$ helper 17 (Th17) cells that can exacerbate inflammation and disease severity. However, the biological effects of lactate on the APCs under inflammatory conditions are much less understood. Therefore, further investigation requires a more detailed understanding of the lactate effect on different subsets of immune cells under inflammatory versus steady-state conditions.

\section{LACTATE IN REGULATING IMMUNE RESPONSES TO INFECTIONS}

Emerging studies show that lactate modulates immune responses to infections. As discussed above, DCs and macrophages recognize different pathogens through PRRs, and signaling through these receptors leads to increased glycolysis and increased lactate production. Sepsis is a common and frequently fatal clinical condition characterized by an initial systemic inflammatory response to infection followed by an immunosuppressive phase (128). A recent study utilizing murine models of sepsis has shown that, lactate-GPR81-mediated signaling suppresses the expression of proinflammatory cytokines and induces alternative polarization of macrophages to M2 phenotype $(39,98)$. Similarly, lactate-induced activation of GPR109a improves survival in mice with sepsis (129). However, the effects of lactate on the functions of DCs and other immune cells in sepsis are unknown. RIG-I-like receptor (RLRs)- 
mediated signaling is necessary for Type I interferon (IFN) production and this is critical for augmenting host immunity for viral clearance and cancer immune surveillance (10). A recent study has shown that lactate can affect IFN production by negatively regulating the RLR- MAVS-RIG-I pathway (130). Besides, blocking lactate production or metabolism increased type I IFN production with enhanced viral clearance (130). Several pathogens can modulate DC and macrophage function as a mechanism to evade host immune response, resulting in chronic infections such as TB, HIV, HCV, HBV, and SIV (10). However, the role of lactate in the regulation of innate and adaptive immune responses to chronic infections is unknown. In this context, a recent study has shown that in response to Mycobacterium tuberculosis ( $M t b)$ infection, macrophages switch from pyruvate oxidation to reduction of pyruvate into lactate (131). Besides, Mtb utilizes intracellular lactate as an energy source for growth in macrophages (131). This metabolic switch in macrophages to Mtb infection also increases anti-inflammatory factors such as IL-10 (132). Anti-inflammatory factors produced by APCs play a significant role in establishing chronic infections (10). Collectively, these studies showed that lactate could modulate the immune responses to infections.

\section{LACTATE SIGNALING IN TUMOR- INDUCED IMMUNE TOLERANCE}

Tumors express self-antigens that actively suppress host antitumor immune responses $(114,133)$. Increased lactate levels positively correlate with tumor grade, progression, recurrence, metastasis, and poor prognosis in several types of cancer $(13,134$, 135). As discussed above, lactate secreted by the tumor cells suppresses immune responses by modulating the phenotype and functions of DCs and macrophages in the TME $(136,137)$. Besides, high lactate levels in the TME impart an antiinflammatory phenotype on APCs, contributing to immune suppression. Lactate also promotes tumor progression by inducing the prostaglandin E2 (PGE2) synthesis and cyclooxygenase 2 (COX2) upregulation in monocytes (65). PGE2 is a potent immunomodulator that exhibits both proinflammatory and anti-inflammatory effects on DCs and macrophages. Tumors exploit lactate-mediated signaling to effectively suppress host antitumor immune responses $(1,138)$. DCs and macrophages in the TME express lactate receptors GPR81 and GPR132 (32, 38). The importance of lactatemediated signaling in controlling antitumor immune responses was demonstrated in a study using GPR81 knockout mice (32). Accordingly, GPR81-deficiency in mice resulted in delayed tumor growth and significantly reduced tumor burden in a syngeneic transplant model and a constitutive breast cancer model in mice (32). Tumor DCs from these mice displayed enhanced activation and increased expression of proinflammatory cytokines such as IL-6 and IL-12 (32). pDCs produce type I IFN and are critical for antitumor immunity. However, pDCs in the TME are dysfunctional and produce low levels of IFNo, which is partly due to lactate in the TME (38). The lactate effect on pDC dysfunction is dependent on GPR81 Signaling and MCTs.
Besides, lactate signaling in pDCs induced regulatory $\mathrm{T}$ Cell induction by regulating the tryptophan metabolism. Like DCs, macrophages in the TME exert potent effects on cancer metastasis and antitumor immunity. Similar to GPR81, lactate signaling via GPR132 in macrophages promotes tumor growth and metastasis (41). Consistent with these observations, mice deficient in GPR132 displayed a significant reduction in tumor burden and breast cancer metastasis. However, the underlying molecular mechanisms are unknown. In addition to APCs, lactate can suppress antitumor immune responses by modulating the functions of other immune cells $(67,70,71,83,84)$. In summary, these studies reveal an exciting and unappreciated role for lactate in contributing to immune suppression against tumors through different effector mechanisms.

\section{TARGETING THE LACTATE SIGNALING PATHWAY FOR IMMUNE MODULATION AND IMMUNOTHERAPY}

There is considerable interest in the lactate signaling pathway as a therapeutic target, especially as a treatment for inflammatory diseases and cancer. Studies involving human cancers and inflammatory diseases strongly suggest that targeting the lactate signaling pathway and lactate metabolism is a promising approach to overcome immune evasion by tumors and suppressing immune-mediated inflammatory diseases. These strategies include targeting signaling (GPR81/GPR132 antagonists), lactate transporters (MCT inhibitors), and lactate metabolism (LDH inhibitors). In addition, pharmacological activators and inhibitors of the lactate signaling pathway exist, and several of them are currently in clinical testing. Here, we will briefly discuss preclinical studies related to the effects of blocking the lactate signaling pathway and lactate metabolism on antitumor immunity and autoimmunity.

\section{TARGETING LACTATE-GPR81/GPR132 SIGNALING}

Lactate receptor expression is upregulated in several types of cancer and lactate signaling plays a vital role in tumor development, progression, and metastasis $(13,89,90)$. As discussed above, Lactate receptor-mediated signaling in immune cells contributes to the suppression of antitumor immune responses. Thus, blocking specific lactate ligand with cognate GPR81/GPR132 receptors represents a potential strategy to restrain tumor cell proliferation while boosting the antitumor immunity. In this context, a recent study using a 4T1 breast cancer model has shown that intratumoral injection of a GPR81 inhibitor along with an MCT inhibitor resulted in a significant reduction in tumor burden in mice (38). Another critical study has demonstrated that blocking GPR132 signaling in macrophages markedly reduced tumor burden, progression, and breast cancer metastasis in mice (41) 
Likewise, pharmacological inhibition of GPR132 signaling had a similar effect on tumor burden and antitumor immune responses (139).

On the other hand, activating the GPR81 pathway in APCs may help prevent and treat immune cell-mediated inflammatory diseases such as IBD, hepatitis, and pancreatitis. In this context, our previous study has shown that pharmacological activation of the GPR81 pathway suppressed intestinal inflammation by inducing Treg responses and limiting pathological Th1/Th17 responses. Preclinical studies have shown that lactate treatment suppresses inflammatory responses in the intestine and mitigates intestinal injury (121). Oral administration of lactate had a similar suppressive effect on inflammation-associated gastric injury (140). Likewise, treatment with the GPR81 agonist, 3,5-dihydroxybenzoic acid, ameliorated DSS-induced colitis and reduced inflammationassociated injury in the colon (30). Other studies have shown that pharmacological activation of the GPR81 pathway suppresses inflammation and inflammation-associated tissue injury in other immune cell-mediated inflammatory diseases (31, 141-143). Further studies in understanding the lactate signaling networks in a context-dependent manner will aid in the development of effective treatments for many inflammatory diseases.

\section{TARGETING LACTATE TRANSPORTERS}

The second strategy to augment antitumor immune responses involves blocking lactate transporters using MCT inhibitors (22, 144). MCTs are highly expressed in tumors and positively correlate with cancer patients' poor outcomes $(22,144)$. Besides, MCTs promote migration and invasion processes in several cancer types, including lung and breast cancers $(22,144)$. Several studies have examined antitumor immune responses by blocking lactate transport into the APCs using clinically relevant murine tumor models. Blockade of cytosolic transport of lactate in pDCs using AR-C155858 (MCT inhibitor) restored the IFN $\alpha$ production and augmented the immune responses against 4T1 tumors in mice. Furthermore, intratumoral injection of AR-C155858 caused a significant reduction in $4 \mathrm{~T} 1$ tumor burden in mice (38). Immune checkpoint inhibitors are currently used in cancer immune therapy to enhance immune responses. Another study has shown that silencing MCT1 and MCT4 can restore T cell-induced immune function and boost the immune response to immune checkpoint inhibitors in melanoma patients (75). Also, treatment of Raji xenograft-bearing severe combined immunodeficiency mice with AZD3965 led to inhibition of tumor growth with increased tumor immune cell infiltration involving DCs and natural killer cells (145). MCT1/2 inhibitors are currently in Phase I/II clinical trials to treat patients with advanced prostate cancer, gastric cancer, or diffuse large B-cell lymphoma (146-150). Collectively these preclinical studies show that drugs that target MCTs alone or in combination with immune checkpoint inhibitors hold much promise as cancer treatments.

In certain autoimmune diseases such as arthritis and MS, MCTs play an inflammatory role. Accumulating evidence shows that blocking lactate efflux or influx has an immunosuppressive effect (151). MCT1/2/4 play a vital role in this, and pharmacological inhibitors of the transporters are attractive targets in these immune-cell mediated inflammatory diseases. Preclinical studies utilizing the murine model of MS have shown that silencing or blocking MCT4 reduced leukocyte infiltration into the CNS and the clinical severity of EAE. Similarly, the silencing of MCT4-inhibited proliferation of RA synovial fibroblast (RASFs) reduced the severity of arthritis in a mouse model of collagen-induced arthritis (152). Further studies utilizing murine models of peritonitis and arthritis have shown that blocking or silencing lactate transporter (SLC5A12) restored the $\mathrm{T}$ cell functions and ameliorated the disease severity $(73,74$, 153). CD147 (EMMPRIN) plays a crucial role in regulating MCT expression by stabilizing and localizing MCTs to the cell membrane. Therefore, disrupting the interaction between CD147 and MCT is also an attractive strategy to regulate immune responses in human diseases. Targeting CD147 has yielded encouraging results in preclinical models of inflammatory diseases $(154,155)$. Studies have shown that the loss of CD147 function decreases the levels of MCT1 and MCT4 proteins and reduces tumor growth (156-158).

\section{TARGETING LACTATE METABOLISM}

The third strategy to augment antitumor immune responses involves targeting lactate metabolism $(23,159)$. LDH-A increases the production of lactate in tumor cells and immune cells resulting in tumor immune escape by inhibiting the function of immune cells $(71,160)$. There is a strong correlation between elevated lactate dehydrogenase (LDH) and poor prognosis in cancer patients. Besides, cancer patients with high LDH levels respond poorly to immunotherapy and other anticancer therapies such as chemotherapy and targeted therapy (159, 161, 162). Thus, targeting the lactate metabolic pathway in immune cells can overcome immune cell dysfunction in the TME. For example, suppressing $\mathrm{LDH}$ activity in macrophages can reprogram M2 phenotype to M1 phenotype (163). Besides, deletion of LDH-A in myeloid cells triggers antitumor immunity in the K-Ras murine lung carcinoma model (164). Likewise, blocking LDH in $\mathrm{CD}^{+} \mathrm{T}$ cells enhances adoptive T cell therapy (70). Genetic disruption or silencing of LDHA and LDHB in tumor cells inhibits tumor growth (165). Thus, targeting lactate metabolism changes lactate levels in the tumor microenvironment and can enhance antitumor immune responses. These targeting strategies collectively provide attractive angles for immunotherapy but warrant a better understanding of the actions of lactate on immune cells under steady-state and inflammatory conditions.

\section{SUMMARY}

Although lactate was initially recognized as a waste product of cellular metabolism, research over the past decade has revealed a fundamental role for this metabolite in shaping the function of the immune cells. Besides, as evidenced from the discussion above, 
lactate in the tissue microenvironment programs APCs and other immune cells to regulate the balance between regulatory and inflammatory responses. Though moderate inflammation is essential to mount normal immune responses, uncontrolled, chronic, and excessive inflammation leads to allergic and autoimmune diseases. Lactate exhibits an inflammatory or antiinflammatory role depending on its effects on immune cell type and disease type. Furthermore, lactate signaling in immune cells could be a critical pathway that links metabolism and immunity. While it is clear that both extracellular and intracellular lactate can program DCs and macrophages to induce robust regulatory immune responses, several important questions remain. For example, how do the lactate signaling pathways regulate adaptive immune responses under homeostatic conditions, inflammation, and cancer?; What are the downstream mediators of the lactateGPR81/GPR132 pathway?; What role do receptor-dependent and independent lactate signaling play in regulating immunity versus tolerance?; How do the lactate act in concert with other signaling pathways in shaping anti-inflammatory and inflammatory immune responses?; and finally, the question of whether

\section{REFERENCES}

1. Certo M, Tsai CH, Pucino V, Ho PC, Mauro C. Lactate Modulation of Immune Responses in Inflammatory Versus Tumour Microenvironments. Nat Rev Immunol (2021) 21:151-61. doi: 10.1038/s41577-020-0406-2

2. Kiran D, Basaraba RJ. Lactate Metabolism and Signaling in Tuberculosis and Cancer: A Comparative Review. Front Cell Infect Microbiol (2021) 11:624607. doi: 10.3389/fcimb.2021.624607

3. Pucino V, Bombardieri M, Pitzalis C, Mauro C. Lactate at the Crossroads of Metabolism, Inflammation, and Autoimmunity. Eur J Immunol (2017) 47:14-21. doi: 10.1002/eji.201646477

4. Pulendran B, Tang H, Denning TL. Division of Labor, Plasticity, and Crosstalk Between Dendritic Cell Subsets. Curr Opin Immunol (2008) 20:61-7. doi: 10.1016/j.coi.2007.10.009

5. Murray PJ, Wynn TA. Protective and Pathogenic Functions of Macrophage Subsets. Nat Rev Immunol (2011) 11:723-37. doi: 10.1038/nri3073

6. Brown CC, Gudjonson H, Pritykin Y, Deep D, Lavallee VP, Mendoza A, et al. Transcriptional Basis of Mouse and Human Dendritic Cell Heterogeneity. Cell (2019) 179:846-63.e24. doi: 10.1016/j.cell.2019.09.035

7. Pulendran B. The Varieties of Immunological Experience: of Pathogens, Stress, and Dendritic Cells. Annu Rev Immunol (2015) 33:563-606. doi: 10.1146/annurev-immunol-020711-075049

8. Varol C, Mildner A, Jung S. Macrophages: Development and Tissue Specialization. Annu Rev Immunol (2015) 33:643-75. doi: 10.1146/ annurev-immunol-032414-112220

9. Murphy TL, Grajales-Reyes GE, Wu X, Tussiwand R, Briseno CG, Iwata A, et al. Transcriptional Control of Dendritic Cell Development. Annu Rev Immunol (2016) 34:93-119. doi: 10.1146/annurev-immunol-032713-120204

10. Manicassamy S, Pulendran B. Modulation of Adaptive Immunity With Toll-like Receptors. Semin Immunol (2009) 21:185-93. doi: 10.1016/j.smim.2009.05.005

11. Manicassamy S, Pulendran B. Dendritic Cell Control of Tolerogenic Responses. Immunol Rev (2011) 241:206-27. doi: 10.1111/j.1600-065X.2011.01015.x

12. Kelly B, O’Neill LA. Metabolic Reprogramming in Macrophages and Dendritic Cells in Innate Immunity. Cell Res (2015) 25:771-84. doi: 10.1038/cr.2015.68

13. Brown TP, Ganapathy V. Lactate/GPR81 Signaling and Proton Motive Force in Cancer: Role in Angiogenesis, Immune Escape, Nutrition, and Warburg Phenomenon. Pharmacol Ther (2020) 206:107451. doi: 10.1016/ j.pharmthera.2019.107451

14. Weiss HJ, Angiari S. Metabolite Transporters as Regulators of Immunity. Metabolites (2020) 10:418-36. doi: 10.3390/metabo10100418 persistent chronic infections such as HIV, HCV or TB exploit the lactate-mediated signaling pathways and, if so, whether blocking this pathway would enhance the immune response is unknown. Addressing these questions will guide the rational design of therapeutic vaccines to reprogram the innate and adaptive immune system towards autoimmune disease tolerance or enhance immune responses against cancer and chronic infections.

\section{AUTHOR CONTRIBUTIONS}

IM, PP, MT and SM have performed bibliographic researches and drafted the manuscript. All authors contributed to the article and approved the submitted version.

\section{FUNDING}

We gratefully acknowledge the generous support from Augusta University Intramural Grants Program and the National Institutes of Health (DK123360) for our work.
15. Wculek SK, Khouili SC, Priego E, Heras-Murillo I, Sancho D. Metabolic Control of Dendritic Cell Functions: Digesting Information. Front Immunol (2019) 10:775. doi: 10.3389/fimmu.2019.00775

16. Jantsch J, Chakravortty D, Turza N, Prechtel AT, Buchholz B, Gerlach RG, et al. Hypoxia and Hypoxia-Inducible Factor-1 Alpha Modulate Lipopolysaccharide-Induced Dendritic Cell Activation and Function. J Immunol (2008) 180:4697-705. doi: 10.4049/jimmunol.180.7.4697

17. Fliesser M, Morton CO, Bonin M, Ebel F, Hunniger K, Kurzai O, et al. Hypoxia-Inducible Factor 1alpha Modulates Metabolic Activity and Cytokine Release in anti-Aspergillus Fumigatus Immune Responses Initiated by Human Dendritic Cells. Int J Med Microbiol (2015) 305:86573. doi: 10.1016/j.ijmm.2015.08.036

18. Lawless SJ, Kedia-Mehta N, Walls JF, McGarrigle R, Convery O, Sinclair LV, et al. Glucose Represses Dendritic Cell-Induced T Cell Responses. Nat Commun (2017) 8:15620. doi: 10.1038/ncomms 15620

19. Lu H, Forbes RA, Verma A. Hypoxia-Inducible Factor 1 Activation by Aerobic Glycolysis Implicates the Warburg Effect in Carcinogenesis. J Biol Chem (2002) 277:23111-5. doi: 10.1074/jbc.M202487200

20. Colegio OR, Chu NQ, Szabo AL, Chu T, Rhebergen AM, Jairam V, et al. Functional Polarization of Tumour-Associated Macrophages by TumourDerived Lactic Acid. Nature (2014) 513:559-63. doi: 10.1038/nature13490

21. Halestrap AP. The SLC16 Gene Family - Structure, Role and Regulation in Health and Disease. Mol Aspects Med (2013) 34:337-49. doi: 10.1016/ j.mam.2012.05.003

22. Sun X, Wang M, Wang M, Yao L, Li X, Dong H, et al. Role of ProtonCoupled Monocarboxylate Transporters in Cancer: From Metabolic Crosstalk to Therapeutic Potential. Front Cell Dev Biol (2020) 8:651. doi: 10.3389/fcell.2020.00651

23. Doherty JR, Cleveland JL. Targeting Lactate Metabolism for Cancer Therapeutics. J Clin Invest (2013) 123:3685-92. doi: 10.1172/JCI69741

24. Fiaschi T, Marini A, Giannoni E, Taddei ML, Gandellini P, De Donatis A, et al. Reciprocal Metabolic Reprogramming Through Lactate Shuttle Coordinately Influences Tumor-Stroma Interplay. Cancer Res (2012) 72:5130-40. doi: 10.1158/0008-5472.CAN-12-1949

25. Feng J, Yang H, Zhang Y, Wei H, Zhu Z, Zhu B, et al. Tumor Cell-Derived Lactate Induces TAZ-dependent Upregulation of PD-L1 Through GPR81 in Human Lung Cancer Cells. Oncogene (2017) 36:5829-39. doi: 10.1038/ onc. 2017.188

26. Liu C, Wu J, Zhu J, Kuei C, Yu J, Shelton J, et al. Lactate Inhibits Lipolysis in Fat Cells Through Activation of an Orphan G-Protein-Coupled Receptor, GPR81. J Biol Chem (2009) 284:2811-22. doi: 10.1074/jbc.M806409200 
27. Wanders D, Graff EC, Judd RL. Effects of High Fat Diet on GPR109A and GPR81 Gene Expression. Biochem Biophys Res Commun (2012) 425:278-83. doi: 10.1016/j.bbrc.2012.07.082

28. Morland C, Lauritzen KH, Puchades M, Holm-Hansen S, Andersson K, Gjedde A, et al. The Lactate Receptor, G-protein-coupled Receptor 81/ Hydroxycarboxylic Acid Receptor 1: Expression and Action in Brain. J Neurosci Res (2015) 93:1045-55. doi: 10.1002/jnr.23593

29. Errea A, Cayet D, Marchetti P, Tang C, Kluza J, Offermanns S, et al. Lactate Inhibits the Pro-Inflammatory Response and Metabolic Reprogramming in Murine Macrophages in a GPR81-Independent Manner. PloS One (2016) 11: e0163694. doi: 10.1371/journal.pone.0163694

30. Ranganathan P, Shanmugam A, Swafford D, Suryawanshi A, Bhattacharjee P, Hussein MS, et al. GPR81, a Cell-Surface Receptor for Lactate, Regulates Intestinal Homeostasis and Protects Mice From Experimental Colitis. J Immunol (2018) 200:1781-9. doi: 10.4049/jimmunol.1700604

31. Hoque R, Farooq A, Ghani A, Gorelick F, Mehal WZ. Lactate Reduces Liver and Pancreatic Injury in Toll-like Receptor- and Inflammasome-Mediated Inflammation Via GPR81-mediated Suppression of Innate Immunity. Gastroenterology (2014) 146:1763-74. doi: 10.1053/j.gastro.2014.03.014

32. Brown TP, Bhattacharjee P, Ramachandran S, Sivaprakasam S, Ristic B, Sikder MOF, et al. The Lactate Receptor GPR81 Promotes Breast Cancer Growth Via a Paracrine Mechanism Involving Antigen-Presenting Cells in the Tumor Microenvironment. Oncogene (2020) 39:3292-304. doi: 10.1038/ s41388-020-1216-5

33. Jeninga EH, Bugge A, Nielsen R, Kersten S, Hamers N, Dani C, et al. Peroxisome Proliferator-Activated Receptor Gamma Regulates Expression of the Anti-Lipolytic G-protein-coupled Receptor 81 (GPR81/Gpr81). J Biol Chem (2009) 284:26385-93. doi: 10.1074/jbc.M109.040741

34. Wahli W, Michalik L. Ppars at the Crossroads of Lipid Signaling and Inflammation. Trends Endocrinol Metab (2012) 23:351-63. doi: 10.1016/ j.tem.2012.05.001

35. Manoharan I, Suryawanshi A, Hong Y, Ranganathan P, Shanmugam A, Ahmad S, et al. Homeostatic PPARalpha Signaling Limits Inflammatory Responses to Commensal Microbiota in the Intestine. J Immunol (2016) 196:4739-49. doi: 10.4049/jimmunol.1501489

36. Mathew D, Torres RM. Lysophosphatidic Acid Is an Inflammatory Lipid Exploited by Cancers for Immune Evasion Via Mechanisms Similar and Distinct From CTLA-4 and PD-1. Front Immunol (2020) 11:531910. doi: 10.3389/fimmu.2020.531910

37. Xie Q, Zhu Z, He Y, Zhang Z, Zhang Y, Wang Y, et al. A Lactate-Induced Snail/STAT3 Pathway Drives GPR81 Expression in Lung Cancer Cells. Biochim Biophys Acta Mol Basis Dis (2020) 1866:165576. doi: 10.1016/ j.bbadis.2019.165576

38. Raychaudhuri D, Bhattacharya R, Sinha BP, Liu CSC, Ghosh AR, Rahaman $\mathrm{O}$, et al. Lactate Induces Pro-Tumor Reprogramming in Intratumoral Plasmacytoid Dendritic Cells. Front Immunol (2019) 10:1878. doi: 10.3389/fimmu.2019.01878

39. Yang K, Xu J, Fan M, Tu F, Wang X, Ha T, et al. Lactate Suppresses Macrophage Pro-Inflammatory Response to LPS Stimulation by Inhibition of YAP and NF-kappaB Activation Via GPR81-Mediated Signaling. Front Immunol (2020) 11:587913. doi: 10.3389/fimmu.2020.587913

40. Samuvel DJ, Sundararaj KP, Nareika A, Lopes-Virella MF, Huang Y. Lactate Boosts TLR4 Signaling and NF-kappaB Pathway-Mediated Gene Transcription in Macrophages Via Monocarboxylate Transporters and MD-2 Up-Regulation. J Immunol (2009) 182:2476-84. doi: 10.4049/jimmunol.0802059

41. Chen P, Zuo H, Xiong H, Kolar MJ, Chu Q, Saghatelian A, et al. Gpr132 Sensing of Lactate Mediates Tumor-Macrophage Interplay to Promote Breast Cancer Metastasis. Proc Natl Acad Sci U.S.A. (2017) 114:580-5. doi: $10.1073 /$ pnas. 1614035114

42. Bolick DT, Skaflen MD, Johnson LE, Kwon SC, Howatt D, Daugherty A, et al. G2A Deficiency in Mice Promotes Macrophage Activation and Atherosclerosis. Circ Res (2009) 104:318-27. doi: 10.1161/CIRCRESAHA.108.181131

43. Murakami N, Yokomizo T, Okuno T, Shimizu T. G2A Is a Proton-Sensing G-protein-Coupled Receptor Antagonized by Lysophosphatidylcholine. J Biol Chem (2004) 279:42484-91. doi: 10.1074/jbc.M406561200

44. Kabarowski JH. G2A and LPC: Regulatory Functions in Immunity. Prostaglandins Other Lipid Mediat (2009) 89:73-81. doi: 10.1016/ j.prostaglandins.2009.04.007
45. Radu CG, Yang LV, Riedinger M, Au M, Witte ON. T Cell Chemotaxis to Lysophosphatidylcholine Through the G2A Receptor. Proc Natl Acad Sci USA (2004) 101:245-50. doi: 10.1073/pnas.2536801100

46. Chen J, Yao Y, Gong C, Yu F, Su S, Chen J, et al. CCL18 From TumorAssociated Macrophages Promotes Breast Cancer Metastasis Via PITPNM3. Cancer Cell (2011) 19:541-55. doi: 10.1016/j.ccr.2011.02.006

47. Qian BZ, Pollard JW. Macrophage Diversity Enhances Tumor Progression and Metastasis. Cell (2010) 141:39-51. doi: 10.1016/j.cell.2010.03.014

48. Zeng Z, Mukherjee A, Varghese AP, Yang XL, Chen S, Zhang H. Roles of G Protein-Coupled Receptors in Inflammatory Bowel Disease. World J Gastroenterol (2020) 26:1242-61. doi: 10.3748/wjg.v26.i12.1242

49. Zhao Y, Zhao B, Wang X, Guan G, Xin Y, Sun YD, et al. Macrophage Transcriptome Modification Induced by Hypoxia and Lactate. Exp Ther Med (2019) 18:4811-9. doi: 10.3892/etm.2019.8164

50. Adcock IM. HDAC Inhibitors as Anti-Inflammatory Agents. Br J Pharmacol (2007) 150:829-31. doi: 10.1038/sj.bjp.0707166

51. Latham T, Mackay L, Sproul D, Karim M, Culley J, Harrison DJ, et al. Lactate, a Product of Glycolytic Metabolism, Inhibits Histone Deacetylase Activity and Promotes Changes in Gene Expression. Nucleic Acids Res (2012) 40:4794-803. doi: 10.1093/nar/gks066

52. Wagner W, Ciszewski WM, Kania KD. L- and D-lactate Enhance DNA Repair and Modulate the Resistance of Cervical Carcinoma Cells to Anticancer Drugs Via Histone Deacetylase Inhibition and Hydroxycarboxylic Acid Receptor 1 Activation. Cell Commun Signal (2015) 13:36. doi: 10.1186/s12964-015-0114-x

53. Gottfried E, Kunz-Schughart LA, Ebner S, Mueller-Klieser W, Hoves S, Andreesen R, et al. Tumor-Derived Lactic Acid Modulates Dendritic Cell Activation and Antigen Expression. Blood (2006) 107:2013-21. doi: 10.1182/ blood-2005-05-1795

54. Nasi A, Rethi B. Disarmed by Density: A Glycolytic Break for Immunostimulatory Dendritic Cells? Oncoimmunology (2013) 2:e26744. doi: $10.4161 /$ onci.26744

55. Nasi A, Fekete T, Krishnamurthy A, Snowden S, Rajnavolgyi E, Catrina AI, et al. Dendritic Cell Reprogramming by Endogenously Produced Lactic Acid. J Immunol (2013) 191:3090-9. doi: 10.4049/jimmunol.1300772

56. Pearce EJ, Everts B. Dendritic Cell Metabolism. Nat Rev Immunol (2015) 15:18-29. doi: $10.1038 /$ nri3771

57. Caronni N, Simoncello F, Stafetta F, Guarnaccia C, Ruiz-Moreno JS, Opitz B, et al. Downregulation of Membrane Trafficking Proteins and Lactate Conditioning Determine Loss of Dendritic Cell Function in Lung Cancer. Cancer Res (2018) 78:1685-99. doi: 10.1158/0008-5472.CAN-17-1307

58. Monti M, Vescovi R, Consoli F, Farina D, Moratto D, Berruti A, et al. Plasmacytoid Dendritic Cell Impairment in Metastatic Melanoma by Lactic Acidosis. Cancers (Basel) (2020) 12:2085-109. doi: 10.3390/cancers12082085

59. Sangsuwan R, Thuamsang B, Pacifici N, Allen R, Han H, Miakicheva S, et al. Lactate Exposure Promotes Immunosuppressive Phenotypes in Innate Immune Cells. Cell Mol Bioeng (2020) 13:541-57. doi: 10.1007/s12195020-00652-x

60. Dietl K, Renner K, Dettmer K, Timischl B, Eberhart K, Dorn C, et al. Lactic Acid and Acidification Inhibit TNF Secretion and Glycolysis of Human Monocytes. J Immunol (2010) 184:1200-9. doi: 10.4049/jimmunol.0902584

61. Palucka K, Banchereau J. Cancer Immunotherapy Via Dendritic Cells. Nat Rev Cancer (2012) 12:265-77. doi: 10.1038/nrc3258

62. Chen DS, Mellman I. Oncology Meets Immunology: The Cancer-Immunity Cycle. Immunity (2013) 39:1-10. doi: 10.1016/j.immuni.2013.07.012

63. Guak H, Al Habyan S, Ma EH, Aldossary H, Al-Masri M, Won SY, et al. Glycolytic Metabolism Is Essential for CCR7 Oligomerization and Dendritic Cell Migration. Nat Commun (2018) 9:2463. doi: 10.1038/s41467-01804804-6

64. Goetze K, Walenta S, Ksiazkiewicz M, Kunz-Schughart LA, Mueller-Klieser W. Lactate Enhances Motility of Tumor Cells and Inhibits Monocyte Migration and Cytokine Release. Int J Oncol (2011) 39:453-63. doi: 10.3892/ijo.2011.1055

65. Wei L, Zhou Y, Yao J, Qiao C, Ni T, Guo R, et al. Lactate Promotes PGE2 Synthesis and Gluconeogenesis in Monocytes to Benefit the Growth of Inflammation-Associated Colorectal Tumor. Oncotarget (2015) 6:16198214. doi: $10.18632 /$ oncotarget. 3838

66. Ratter JM, Rooijackers HMM, Hooiveld GJ, Hijmans AGM, de Galan BE, Tack CJ, et al. In Vitro and In Vivo Effects of Lactate on Metabolism and 
Cytokine Production of Human Primary PBMCs and Monocytes. Front Immunol (2018) 9:2564. doi: 10.3389/fimmu.2018.02564

67. Comito G, Iscaro A, Bacci M, Morandi A, Ippolito L, Parri M, et al. Lactate Modulates CD4(+) T-Cell Polarization and Induces an Immunosuppressive Environment, Which Sustains Prostate Carcinoma Progression Via TLR8/ miR21 Axis. Oncogene (2019) 38:3681-95. doi: 10.1038/s41388-019-0688-7

68. Quinn WJ3rd, Jiao J, TeSlaa T, Stadanlick J, Wang Z, Wang L, et al. Lactate Limits T Cell Proliferation Via the NAD(H) Redox State. Cell Rep (2020) 33:108500. doi: 10.1016/j.celrep.2020.108500

69. Wen J, Cheng S, Zhang Y, Wang R, Xu J, Ling Z, et al. Lactate Anions Participate in T Cell Cytokine Production and Function. Sci China Life Sci (2021) 64:534-47. doi: 10.1007/s11427-020-1887-7

70. Hermans D, Gautam S, Garcia-Canaveras JC, Gromer D, Mitra S, Spolski R, et al. Lactate Dehydrogenase Inhibition Synergizes With IL-21 to Promote CD8(+) T Cell Stemness and Antitumor Immunity. Proc Natl Acad Sci USA (2020) 117:6047-55. doi: 10.1073/pnas.1920413117

71. Brand A, Singer K, Koehl GE, Kolitzus M, Schoenhammer G, Thiel A, et al. Ldha-Associated Lactic Acid Production Blunts Tumor Immunosurveillance by $\mathrm{T}$ and NK Cells. Cell Metab (2016) 24:657-71. doi: 10.1016/ j.cmet.2016.08.011

72. Watson MJ, Vignali PDA, Mullett SJ, Overacre-Delgoffe AE, Peralta RM, Grebinoski S, et al. Metabolic Support of Tumour-Infiltrating Regulatory T Cells by Lactic Acid. Nature (2021) 591:645-51. doi: 10.1038/s41586-02003045-2

73. Haas R, Smith J, Rocher-Ros V, Nadkarni S, Montero-Melendez T, D'Acquisto F, et al. Lactate Regulates Metabolic and Pro-inflammatory Circuits in Control of T Cell Migration and Effector Functions. PloS Biol (2015) 13:e1002202. doi: 10.1371/journal.pbio.1002202

74. Pucino V, Certo M, Bulusu V, Cucchi D, Goldmann K, Pontarini E, et al. Lactate Buildup at the Site of Chronic Inflammation Promotes Disease by Inducing Cd4(+) T Cell Metabolic Rewiring. Cell Metab (2019) 30:10551074 e8. doi: 10.1016/j.cmet.2019.10.004

75. Renner K, Bruss C, Schnell A, Koehl G, Becker HM, Fante M, et al. Restricting Glycolysis Preserves T Cell Effector Functions and Augments Checkpoint Therapy. Cell Rep (2019) 29:135-50.e9. doi: 10.1016/ j.celrep.2019.08.068

76. Fischer K, Hoffmann P, Voelkl S, Meidenbauer N, Ammer J, Edinger M, et al. Inhibitory Effect of Tumor Cell-Derived Lactic Acid on Human T Cells. Blood (2007) 109:3812-9. doi: 10.1182/blood-2006-07-035972

77. Li B, Yang Q, Li Z, Xu Z, Sun S, Wu Q, et al. Expression of Monocarboxylate Transporter 1 in Immunosuppressive Macrophages Is Associated With the Poor Prognosis in Breast Cancer. Front Oncol (2020) 10:574787. doi: $10.3389 /$ fonc. 2020.574787

78. Zhang L, Li S. Lactic Acid Promotes Macrophage Polarization Through MCT-HIF1alpha Signaling in Gastric Cancer. Exp Cell Res (2020) 388:111846. doi: 10.1016/j.yexcr.2020.111846

79. Feng R, Morine $\mathrm{Y}$, Ikemoto T, Imura S, Iwahashi S, Saito Y, et al. Nrf2 Activation Drive Macrophages Polarization and Cancer Cell EpithelialMesenchymal Transition During Interaction. Cell Commun Signal (2018) 16:54. doi: 10.1186/s12964-018-0262-x

80. Mu X, Shi W, Xu Y, Xu C, Zhao T, Geng B, et al. Tumor-Derived Lactate Induces M2 Macrophage Polarization Via the Activation of the ERK/STAT3 Signaling Pathway in Breast Cancer. Cell Cycle (2018) 17:428-38. doi: 10.1080/15384101.2018.1444305

81. Lin S, Sun L, Lyu X, Ai X, Du D, Su N, et al. Lactate-Activated Macrophages Induced Aerobic Glycolysis and Epithelial-Mesenchymal Transition in Breast Cancer by Regulation of CCL5-CCR5 Axis: A Positive Metabolic Feedback Loop. Oncotarget (2017) 8:110426-43. doi: 10.18632/oncotarget.22786

82. Gabrilovich DI, Nagaraj S. Myeloid-Derived Suppressor Cells as Regulators of the Immune System. Nat Rev Immunol (2009) 9:162-74. doi: 10.1038/ nri2506

83. Husain Z, Seth P, Sukhatme VP. Tumor-Derived Lactate and MyeloidDerived Suppressor Cells: Linking Metabolism to Cancer Immunology. Oncoimmunology (2013) 2:e26383. doi: 10.4161/onci.26383

84. Yang X, Lu Y, Hang J, Zhang J, Zhang T, Huo Y, et al. Lactate-Modulated Immunosuppression of Myeloid-Derived Suppressor Cells Contributes to the Radioresistance of Pancreatic Cancer. Cancer Immunol Res (2020) 8:1440-51. doi: 10.1158/2326-6066.CIR-20-0111
85. Caslin HL, Abebayehu D, Abdul Qayum A, Haque TT, Taruselli MT, Paez PA, et al. Lactic Acid Inhibits Lipopolysaccharide-Induced Mast Cell Function by Limiting Glycolysis and ATP Availability. J Immunol (2019) 203:453-64. doi: 10.4049/jimmunol.1801005

86. Abebayehu D, Spence AJ, Qayum AA, Taruselli MT, McLeod JJ, Caslin HL, et al. Lactic Acid Suppresses IL-33-Mediated Mast Cell Inflammatory Responses Via Hypoxia-Inducible Factor-1alpha-Dependent miR-155 Suppression. J Immunol (2016) 197:2909-17. doi: 10.4049/jimmunol.1600651

87. Khatib-Massalha E, Bhattacharya S, Massalha H, Biram A, Golan K, Kollet $\mathrm{O}$, et al. Lactate Released by Inflammatory Bone Marrow Neutrophils Induces Their Mobilization Via Endothelial GPR81 Signaling. Nat Commun (2020) 11:3547. doi: 10.1038/s41467-020-17402-2

88. Abebayehu D, Spence AJ, Caslin H, Taruselli M, Haque TT, Kiwanuka KN, et al. Lactic Acid Suppresses IgE-mediated Mast Cell Function In Vitro and In Vivo. Cell Immunol (2019) 341:103918. doi: 10.1016/j.cellimm.2019.04.006

89. Roland CL, Arumugam T, Deng D, Liu SH, Philip B, Gomez S, et al. Cell Surface Lactate Receptor GPR81 Is Crucial for Cancer Cell Survival. Cancer Res (2014) 74:5301-10. doi: 10.1158/0008-5472.CAN-14-0319

90. Lee YJ, Shin KJ, Park SA, Park KS, Park S, Heo K, et al. G-Protein-Coupled Receptor 81 Promotes a Malignant Phenotype in Breast Cancer Through Angiogenic Factor Secretion. Oncotarget (2016) 7:70898-911. doi: 10.18632/ oncotarget. 12286

91. Marin E, Bouchet-Delbos L, Renoult O, Louvet C, Nerriere-Daguin V, Managh AJ, et al. Human Tolerogenic Dendritic Cells Regulate Immune Responses Through Lactate Synthesis. Cell Metab (2019) 30:1075-90.e8. doi: 10.1016/j.cmet.2019.11.011

92. Galluzzi L, Buque A, Kepp O, Zitvogel L, Kroemer G. Immunogenic Cell Death in Cancer and Infectious Disease. Nat Rev Immunol (2017) 17:97-111. doi: 10.1038/nri.2016.107

93. Woo SR, Corrales L, Gajewski TF. Innate Immune Recognition of Cancer. Annu Rev Immunol (2015) 33:445-74. doi: 10.1146/annurev-immunol032414-112043

94. Zelenay S, Reis e Sousa C. Adaptive Immunity After Cell Death. Trends Immunol (2013) 34:329-35. doi: 10.1016/j.it.2013.03.005

95. Li JK, Balic JJ, Yu L, Jenkins B. Tlr Agonists as Adjuvants for Cancer Vaccines. Adv Exp Med Biol (2017) 1024:195-212. doi: 10.1007/978-981-105987-2_9

96. Maisonneuve C, Bertholet S, Philpott DJ, De Gregorio E. Unleashing the Potential of NOD- and Toll-like Agonists as Vaccine Adjuvants. Proc Natl Acad Sci U.S.A. (2014) 111:12294-9. doi: 10.1073/pnas.1400478111

97. Dudek AM, Martin S, Garg AD, Agostinis P. Immature, Semi-Mature, and Fully Mature Dendritic Cells: Toward a DC-Cancer Cells Interface That Augments Anticancer Immunity. Front Immunol (2013) 4:s. doi: 10.3389/ fimmu.2013.00438

98. Wang L, He HW, Xing ZQ, Tang B, Zhou X. Lactate Induces Alternative Polarization (M2) of Macrophages Under Lipopolysaccharide Stimulation In Vitro Through G-protein Coupled Receptor 81. (Engl) (2020) 133:1761-3. doi: 10.1097/CM9.0000000000000955

99. Bottcher JP, Reis ESC. The Role of Type 1 Conventional Dendritic Cells in Cancer Immunity. Trends Cancer (2018) 4:784-92. doi: 10.1016/ j.trecan.2018.09.001

100. Cancel JC, Crozat K, Dalod M, Mattiuz R. Are Conventional Type 1 Dendritic Cells Critical for Protective Antitumor Immunity and How? Front Immunol (2019) 10:9. doi: 10.3389/fimmu.2019.00009

101. Gardner A, Ruffell B. Dendritic Cells and Cancer Immunity. Trends Immunol (2016) 37:855-65. doi: 10.1016/j.it.2016.09.006

102. Roberts EW, Broz ML, Binnewies M, Headley MB, Nelson AE, Wolf DM, et al. Critical Role for CD103(+)/CD141(+) Dendritic Cells Bearing CCR7 for Tumor Antigen Trafficking and Priming of T Cell Immunity in Melanoma. Cancer Cell (2016) 30:324-36. doi: 10.1016/j.ccell.2016.06.003

103. Salmon H, Idoyaga J, Rahman A, Leboeuf M, Remark R, Jordan S, et al. Expansion and Activation of CD103(+) Dendritic Cell Progenitors at the Tumor Site Enhances Tumor Responses to Therapeutic Pd-L1 and BRAF Inhibition. Immunity (2016) 44:924-38. doi: 10.1016/j.immuni.2016.03.012

104. Engelhardt JJ, Boldajipour B, Beemiller P, Pandurangi P, Sorensen C, Werb $Z$, et al. Marginating Dendritic Cells of the Tumor Microenvironment CrossPresent Tumor Antigens and Stably Engage Tumor-Specific T Cells. Cancer Cell (2012) 21:402-17. doi: 10.1016/j.ccr.2012.01.008 
105. Leite TC, Coelho RG, Da Silva D, Coelho WS, Marinho-Carvalho MM, SolaPenna M. Lactate Downregulates the Glycolytic Enzymes Hexokinase and Phosphofructokinase in Diverse Tissues From Mice. FEBS Lett (2011) 585:92-8. doi: 10.1016/j.febslet.2010.11.009

106. Joffre OP, Segura E, Savina A, Amigorena S. Cross-Presentation by Dendritic Cells. Nat Rev Immunol (2012) 12:557-69. doi: 10.1038/nri3254

107. Pulendran B, Tang H, Manicassamy S. Programming Dendritic Cells to Induce $\mathrm{T}(\mathrm{H}) 2$ and Tolerogenic Responses. Nat Immunol (2010) 11:647-55. doi: $10.1038 /$ ni.1894

108. Hong Y, Manoharan I, Suryawanshi A, Shanmugam A, Swafford D, Ahmad S, et al. Deletion of LRP5 and LRP6 in Dendritic Cells Enhances Antitumor Immunity. Oncoimmunology (2016) 5:e1115941. doi: 10.1080/ 2162402X.2015.1115941

109. Hong Y, Manoharan I, Suryawanshi A, Majumdar T, Angus-Hill ML, Koni PA, et al. Beta-Catenin Promotes Regulatory T-cell Responses in Tumors by Inducing Vitamin A Metabolism in Dendritic Cells. Cancer Res (2015) 75:656-65. doi: 10.1158/0008-5472.CAN-14-2377

110. Liang X, Fu C, Cui W, Ober-Blobaum JL, Zahner SP, Shrikant PA, et al. BetaCatenin Mediates Tumor-Induced Immunosuppression by Inhibiting CrossPriming of CD8(+) T Cells. J Leukoc Biol (2014) 95:179-90. doi: 10.1189/ jlb.0613330

111. Fu C, Liang X, Cui W, Ober-Blobaum JL, Vazzana J, Shrikant PA, et al. betaCatenin in Dendritic Cells Exerts Opposite Functions in Cross-Priming and Maintenance of CD8+ T Cells Through Regulation of IL-10. Proc Natl Acad Sci USA (2015) 112:2823-8. doi: 10.1073/pnas.1414167112

112. Zhao F, Xiao C, Evans KS, Theivanthiran T, DeVito N, Holtzhausen A, et al. Paracrine Wnt5a-beta-Catenin Signaling Triggers a Metabolic Program That Drives Dendritic Cell Tolerization. Immunity (2018) 48:147-60.e7. doi: 10.1016/j.immuni.2017.12.004

113. Holtzhausen A, Zhao F, Evans KS, Tsutsui M, Orabona C, Tyler DS, et al. Melanoma-Derived Wnt5a Promotes Local Dendritic-Cell Expression of IDO and Immunotolerance: Opportunities for Pharmacologic Enhancement of Immunotherapy. Cancer Immunol Res (2015) 3:1082-95. doi: 10.1158/ 2326-6066.CIR-14-0167

114. Suryawanshi A, Hussein MS, Prasad PD, Manicassamy S. Wnt Signaling Cascade in Dendritic Cells and Regulation of Anti-tumor Immunity. Front Immunol (2020) 11:122. doi: 10.3389/fimmu.2020.00122

115. Suryawanshi A, Tadagavadi RK, Swafford D, Manicassamy S. Modulation of Inflammatory Responses by Wnt/beta-Catenin Signaling in Dendritic Cells: A Novel Immunotherapy Target for Autoimmunity and Cancer. Front Immunol (2016) 7:460. doi: 10.3389/fimmu.2016.00460

116. Swafford D, Manicassamy S. Wnt Signaling in Dendritic Cells: its Role in Regulation of Immunity and Tolerance. Discov Med (2015) 19:303-10.

117. Manicassamy S, Pulendran B. Retinoic Acid-Dependent Regulation of Immune Responses by Dendritic Cells and Macrophages. Semin Immunol (2009) 21:22-7. doi: 10.1016/j.smim.2008.07.007

118. Okada T, Fukuda S, Hase K, Nishiumi S, Izumi Y, Yoshida M, et al. MicrobiotaDerived Lactate Accelerates Colon Epithelial Cell Turnover in Starvation-Refed Mice. Nat Commun (2013) 4:1654. doi: 10.1038/ncomms2668

119. Garrote GL, Abraham AG, Rumbo M. Is Lactate an Undervalued Functional Component of Fermented Food Products? Front Microbiol (2015) 6:629. doi: 10.3389/fmicb.2015.00629

120. Flint HJ, Duncan SH, Scott KP, Louis P. Links Between Diet, Gut Microbiota Composition and Gut Metabolism. Proc Nutr Soc (2015) 74:13-22. doi: $10.1017 /$ S0029665114001463

121. Iraporda C, Romanin DE, Bengoa AA, Errea AJ, Cayet D, Foligne B, et al. Local Treatment With Lactate Prevents Intestinal Inflammation in the TNBS-Induced Colitis Model. Front Immunol (2016) 7:651. doi: 10.3389/ fimmu.2016.00651

122. Lee YS, Kim TY, Kim Y, Lee SH, Kim S, Kang SW, et al. Microbiota-Derived Lactate Accelerates Intestinal Stem-Cell-Mediated Epithelial Development. Cell Host Microbe (2018) 24:833-46.e6. doi: 10.1016/j.chom.2018.11.002

123. Swafford D, Shanmugam A, Ranganathan P, Manoharan I, Hussein MS, Patel N, et al. The Wnt-beta-Catenin-IL-10 Signaling Axis in Intestinal Apcs Protects Mice From Colitis-Associated Colon Cancer in Response to Gut Microbiota. J Immunol (2020) 205:2265-75. doi: 10.4049/jimmunol.1901376

124. Swafford D, Shanmugam A, Ranganathan P, Hussein MS, Koni PA, Prasad $\mathrm{PD}$, et al. Canonical Wnt Signaling in $\mathrm{CD} 11 \mathrm{c}(+)$ Apcs Regulates Microbiota-
Induced Inflammation and Immune Cell Homeostasis in the Colon. J Immunol (2018) 200:3259-68. doi: 10.4049/jimmunol.1701086

125. Frasch SC, McNamee EN, Kominsky D, Jedlicka P, Jakubzick C, Zemski Berry K, et al. G2a Signaling Dampens Colitic Inflammation Via Production of IFN-Gamma. J Immunol (2016) 197:1425-34. doi: 10.4049/jimmunol. 1600264

126. Kaushik DK, Bhattacharya A, Mirzaei R, Rawji KS, Ahn Y, Rho JM, et al. Enhanced Glycolytic Metabolism Supports Transmigration of BrainInfiltrating Macrophages in Multiple Sclerosis. J Clin Invest (2019) 129:3277-92. doi: 10.1172/JCI124012

127. Tak PP, Bresnihan B. The Pathogenesis and Prevention of Joint Damage in Rheumatoid Arthritis: Advances From Synovial Biopsy and Tissue Analysis. Arthritis Rheum (2000) 43:2619-33. doi: 10.1002/1529-0131(200012) 43:12<2619::AID-ANR1>3.0.CO;2-V

128. Nolt B, Tu F, Wang X, Ha T, Winter R, Williams DL, et al. Lactate and Immunosuppression in Sepsis. Shock (2018) 49:120-5. doi: 10.1097/ SHK.0000000000000958

129. Takakura A, Zandi-Nejad K. Lactate-Induced Activation of HCA2 Improves Survival in Mice With Sepsis. FASEB J (2019) 33:7625-34. doi: 10.1096/ fj.201801982R

130. Zhang W, Wang G, Xu ZG, Tu H, Hu F, Dai J, et al. Lactate Is a Natural Suppressor of RLR Signaling by Targeting Mavs. Cell (2019) 178:176-89.e15. doi: 10.1016/j.cell.2019.05.003

131. Billig S, Schneefeld M, Huber C, Grassl GA, Eisenreich W, Bange FC. Lactate Oxidation Facilitates Growth of Mycobacterium Tuberculosis in Human Macrophages. Sci Rep (2017) 7:6484. doi: 10.1038/s41598-017-05916-7

132. Hackett EE, Charles-Messance H, O'Leary SM, Gleeson LE, Munoz-Wolf N, Case S, et al. Mycobacterium Tuberculosis Limits Host Glycolysis and IL1beta by Restriction of PFK-M Via Microrna-21. Cell Rep (2020) 30:124-136 e4. doi: 10.1016/j.celrep.2019.12.015

133. Rabinovich GA, Gabrilovich D, Sotomayor EM. Immunosuppressive Strategies That Are Mediated by Tumor Cells. Annu Rev Immunol (2007) 25:267-96. doi: 10.1146/annurev.immunol.25.022106.141609

134. de la Cruz-Lopez KG, Castro-Munoz LJ, Reyes-Hernandez DO, GarciaCarranca A, Manzo-Merino J. Lactate in the Regulation of Tumor Microenvironment and Therapeutic Approaches. Front Oncol (2019) 9:1143. doi: 10.3389/fonc.2019.01143

135. Perez-Tomas R, Perez-Guillen I. Lactate in the Tumor Microenvironment: An Essential Molecule in Cancer Progression and Treatment. Cancers (Basel) (2020) 12:3244-73. doi: 10.3390/cancers12113244

136. Stone SC, Rossetti RAM, Alvarez KLF, Carvalho JP, Margarido PFR, Baracat EC, et al. Lactate Secreted by Cervical Cancer Cells Modulates Macrophage Phenotype. J Leukoc Biol (2019) 105:1041-54. doi: 10.1002/JLB.3A0718274RR

137. Nenu I, Gafencu GA, Popescu T, Kacso G. Lactate - A New Frontier in the Immunology and Therapy of Prostate Cancer. J Cancer Res Ther (2017) 13:406-11. doi: 10.4103/0973-1482.163692

138. Romero-Garcia S, Moreno-Altamirano MM, Prado-Garcia H, SanchezGarcia FJ. Lactate Contribution to the Tumor Microenvironment: Mechanisms, Effects on Immune Cells and Therapeutic Relevance. Front Immunol (2016) 7:52. doi: 10.3389/fimmu.2016.00052

139. Cheng WY, Huynh H, Chen P, Pena-Llopis S, Wan Y. Macrophage PPARgamma Inhibits Gpr132 to Mediate the Anti-Tumor Effects of Rosiglitazone. Elife (2016) 5:18501-21. doi: 10.7554/eLife.18501

140. Huang Y, Zhang J, Dong R, Ji X, Jiang Y, Cen J, et al. Lactate as a Metabolite From Probiotic Lactobacilli Mitigates Ethanol-Induced Gastric Mucosal Injury: An In Vivo Study. BMC Complement Med Ther (2021) 21:26. doi: 10.1186/s12906-020-03198-7

141. Madaan A, Nadeau-Vallee M, Rivera JC, Obari D, Hou X, Sierra EM, et al. Lactate Produced During Labor Modulates Uterine Inflammation Via GPR81 (Hcal). Am J Obstet Gynecol (2017) 216:60. doi: 10.1016/j.ajog.2016.09.072

142. Wallenius K, Thalen P, Bjorkman JA, Johannesson P, Wiseman J, Bottcher G, et al. Involvement of the Metabolic Sensor GPR81 in Cardiovascular Control. JCI Insight (2017) 292564-82. doi: 10.1172/jci.insight.92564

143. Jones NK, Stewart K, Czopek A, Menzies RI, Thomson A, Moran CM, et al. Endothelin-1 Mediates the Systemic and Renal Hemodynamic Effects of GPR81 Activation. Hypertension (2020) 75:1213-22. doi: 10.1161/ HYPERTENSIONAHA.119.14308 
144. Payen VL, Mina E, Van Hee VF, Porporato PE, Sonveaux P. Monocarboxylate Transporters in Cancer. Mol Metab (2020) 33:48-66. doi: 10.1016/j.molmet.2019.07.006

145. Beloueche-Babari M, Casals Galobart T, Delgado-Goni T, Wantuch S, Parkes HG, Tandy D, et al. Monocarboxylate Transporter 1 Blockade With AZD3965 Inhibits Lipid Biosynthesis and Increases Tumour Immune Cell Infiltration. Br J Cancer (2020) 122:895-903. doi: 10.1038/s41416-019-0717-x

146. Fisel P, Schaeffeler E, Schwab M. Clinical and Functional Relevance of the Monocarboxylate Transporter Family in Disease Pathophysiology and Drug Therapy. Clin Transl Sci (2018) 11:352-64. doi: 10.1111/cts.12551

147. Noble RA, Bell N, Blair H, Sikka A, Thomas H, Phillips N, et al. Inhibition of Monocarboxyate Transporter 1 by AZD3965 as a Novel Therapeutic Approach for Diffuse Large B-cell Lymphoma and Burkitt Lymphoma. Haematologica (2017) 102:1247-57. doi: 10.3324/haematol.2016.163030

148. Benjamin D, Robay D, Hindupur SK, Pohlmann J, Colombi M, El-Shemerly MY, et al. Dual Inhibition of the Lactate Transporters MCT1 and MCT4 Is Synthetic Lethal With Metformin Due to NAD+ Depletion in Cancer Cells. Cell Rep (2018) 25:3047-58.e4. doi: 10.1016/j.celrep.2018.11.043

149. Lee JY, Lee I, Chang WJ, Ahn SM, Lim SH, Kim HS, et al. MCT4 as a Potential Therapeutic Target for Metastatic Gastric Cancer With Peritoneal Carcinomatosis. Oncotarget (2016) 7:43492-503. doi: 10.18632/oncotarget.9523

150. Guan X, Bryniarski MA, Morris ME. In Vitro and In Vivo Efficacy of the Monocarboxylate Transporter 1 Inhibitor Ar-C155858 in the Murine 4t1 Breast Cancer Tumor Model. AAPS J (2018) 21:3. doi: 10.1208/s12248-0180261-2

151. Murray CM, Hutchinson R, Bantick JR, Belfield GP, Benjamin AD, Brazma D, et al. Monocarboxylate Transporter MCT1 Is a Target for Immunosuppression. Nat Chem Biol (2005) 1:371-6. doi: 10.1038/nchembio744

152. Fujii W, Kawahito Y, Nagahara H, Kukida Y, Seno T, Yamamoto A, et al. Monocarboxylate Transporter 4, Associated With the Acidification of Synovial Fluid, Is a Novel Therapeutic Target for Inflammatory Arthritis. Arthritis Rheumatol (2015) 67:2888-96. doi: 10.1002/art.39270

153. Pucino V, Cucchi D, Mauro C. Lactate Transporters as Therapeutic Targets in Cancer and Inflammatory Diseases. Expert Opin Ther Targets (2018) 22:735-43. doi: 10.1080/14728222.2018.1511706

154. Yurchenko V, Constant S, Eisenmesser E, Bukrinsky M. Cyclophilin-CD147 Interactions: A New Target for Anti-Inflammatory Therapeutics. Clin Exp Immunol (2010) 160:305-17. doi: 10.1111/j.1365-2249.2010.04115.x

155. Zhu X, Song Z, Zhang S, Nanda A, Li G. CD147: A Novel Modulator of Inflammatory and Immune Disorders. Curr Med Chem (2014) 21:2138-45. doi: 10.2174/0929867321666131227163352

156. Le Floch R, Chiche J, Marchiq I, Naiken T, Ilc K, Murray CM, et al. CD147 Subunit of Lactate/H+ Symporters MCT1 and Hypoxia-Inducible MCT4 Is Critical for Energetics and Growth of Glycolytic Tumors. Proc Natl Acad Sci USA (2011) 108:16663-8. doi: 10.1073/pnas.1106123108

157. Baba M, Inoue M, Itoh K, Nishizawa Y. Blocking CD147 Induces Cell Death in Cancer Cells Through Impairment of Glycolytic Energy Metabolism. Biochem Biophys Res Commun (2008) 374:111-6. doi: 10.1016/j.bbrc. 2008.06.122
158. Schneiderhan W, Scheler M, Holzmann KH, Marx M, Gschwend JE, Bucholz M, et al. CD147 Silencing Inhibits Lactate Transport and Reduces Malignant Potential of Pancreatic Cancer Cells in In Vivo and In Vitro Models. Gut (2009) 58:1391-8. doi: 10.1136/gut.2009.181412

159. Van Wilpe S, Koornstra R, Den Brok M, De Groot JW, Blank C, De Vries J, et al. Lactate Dehydrogenase: A Marker of Diminished Antitumor Immunity. Oncoimmunology (2020) 9:1731942. doi: 10.1080/2162402X.2020.1731942

160. Husain Z, Huang Y, Seth P, Sukhatme VP. Tumor-Derived Lactate Modifies Antitumor Immune Response: Effect on Myeloid-Derived Suppressor Cells and NK Cells. J Immunol (2013) 191:1486-95. doi: 10.4049/jimmunol. 1202702

161. Hodi FS, Chiarion-Sileni V, Gonzalez R, Grob JJ, Rutkowski P, Cowey CL, et al. Nivolumab Plus Ipilimumab or Nivolumab Alone Versus Ipilimumab Alone in Advanced Melanoma (CheckMate 067): 4-Year Outcomes of a Multicentre, Randomised, Phase 3 Trial. Lancet Oncol (2018) 19:1480-92. doi: 10.1016/S1470-2045(18)30700-9

162. Long GV, Grob JJ, Nathan P, Ribas A, Robert C, Schadendorf D, et al. Factors Predictive of Response, Disease Progression, and Overall Survival After Dabrafenib and Trametinib Combination Treatment: A Pooled Analysis of Individual Patient Data From Randomised Trials. Lancet Oncol (2016) 17:1743-54. doi: 10.1016/S1470-2045(16)30578-2

163. Song YJ, Kim A, Kim GT, Yu HY, Lee ES, Park MJ, et al. Inhibition of Lactate Dehydrogenase A Suppresses Inflammatory Response in RAW 264. 7 Macrophages Mol Med Rep (2019) 19:629-37. doi: 10.3892/mmr.2018.9678

164. Seth P, Csizmadia E, Hedblom A, Vuerich M, Xie H, Li M, et al. Deletion of Lactate Dehydrogenase-a in Myeloid Cells Triggers Antitumor Immunity. Cancer Res (2017) 77:3632-43. doi: 10.1158/0008-5472.CAN-16-2938

165. Le A, Cooper CR, Gouw AM, Dinavahi R, Maitra A, Deck LM, et al. Inhibition of Lactate Dehydrogenase A Induces Oxidative Stress and Inhibits Tumor Progression. Proc Natl Acad Sci USA (2010) 107:2037-42. doi: 10.1073/pnas.0914433107

Conflict of Interest: The authors declare that the research was conducted in the absence of any commercial or financial relationships that could be construed as a potential conflict of interest.

Publisher's Note: All claims expressed in this article are solely those of the authors and do not necessarily represent those of their affiliated organizations, or those of the publisher, the editors and the reviewers. Any product that may be evaluated in this article, or claim that may be made by its manufacturer, is not guaranteed or endorsed by the publisher.

Copyright (C) 2021 Manoharan, Prasad, Thangaraju and Manicassamy. This is an open-access article distributed under the terms of the Creative Commons Attribution License (CC BY). The use, distribution or reproduction in other forums is permitted, provided the original author(s) and the copyright owner(s) are credited and that the original publication in this journal is cited, in accordance with accepted academic practice. No use, distribution or reproduction is permitted which does not comply with these terms. 